\title{
PHOTOGRAPHIC RECORDS OF CONVERGENCE AND DIVERGENCE.
}

\author{
BY CHARLES H. JUDD.
}

This paper reports a series of photographs in which movements of visual convergence and divergence between two fixed points are studied for several positions of the points, namely, in the median plane between the eyes, in certain lateral positions, and especially in the position in which the two points lie directly in the axis of vision of one eye. Five subjects were examined, among them one who was blind in one eye, and consequently exhibited none of the normal forms of binocular convergence and divergence. It is shown by these photographs that there are different tendencies of behavior exhibited by the single eyes of different individuals. There are also differences in the binocular adjustments of different individuals which are probably dependent upon muscular differences in their eyes. All subjects agreed in exhibiting a tendency which is opposed to that of convergent and divergent movements in that they tend to move the two eyes in the same lateral direction. Furtiermore, all subjects agree in showing a long and difficult form of adjustment in binocular convergence and divergence. Monocular adjustments are much simpler in type. The report includes certain accounts of voluntary convergence and divergence and concludes with a theoretical discussion in which the theory of coordination of sensory and motor factors is substituted for any analytical description of visual fusion.

The method employed in the investigation to be reported in this paper is in general the same as that reported in the earlier number of this volume of Yale Psychological Studies. ${ }^{1}$ By means of a kinetoscope camera the eyes were photographed during movement, a small piece of Chinese white being placed upon the cornea so as to mark clearly in the photographs the exact position of the eye. The double camera there reported, with films which are alternately exposed, was employed throughout, though the figures presented in this article are made up from only one of the films. It is not necessary in reporting the distance and direction of the movements to utilize the results from both films, though in determining certain time relations reference will be made to the double record.

An important modification was introduced in the apparatus

${ }^{1}$ Monograph Supplement No. 29 of the Psychological Review. Yale Psychological Studies, N. S., Vol. I., No. I., pp. 1-16. 
in that the camera was driven by a mechanical device. The irregularity which was apparent in the photographic series with even the most carefully trained hand movement was pointed out in the earlier paper. This irregularity has been entirely removed by the mechanical device sketched in Fig. 97 . This consists of a large balance wheel $F$ which is driven by an electric motor. The heavy balance wheel is necessary in order to maintain uniform motion when the camera is thrown into gearing with the driving apparatus. The balance wheel carries a hollow cone into which a solid cone $(W)$ may be firmly set from above. The solid cone is in turn connected with the shaft $(S)$ which drives the camera. The camera does not appear in the figure, it stands above the parts here shown. By means of the handle $(H)$, which holds the solid cone in a ball-

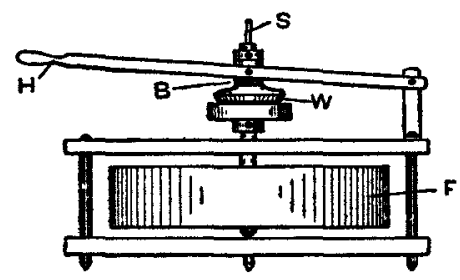

FIG. 97 .

bearing collar, the solid cone may be lifted out of the hollow cone, when the shaft $(S)$ will be uncoupled from the driving wheel. On the other hand, when the solid cone is set firmly into the hollow cone the shaft $(S)$ will immediately be set in operation at the full speed of the driving wheel. The upward and downward movement of the shaft is taken up in a slot device at the upper end of the shaft. This form of driving apparatus makes it possible to begin a series of photographs without any delay such as would be experienced if the driving shaft were set into gradual motion. This is evidently advantageous, for it not only economizes the first and last part of the film while securing photographs at a regular rate of exposure, but it makes it possible to begin at the point of the observer's movements which will be most advantageous, with a certainty that the earliest movements will be fully recorded on the film.

In the earlier reports of the photographic methods atten- 
tion was called to the fact that head movements are often present and constitute a matter for consideration in any photographic method of studying eye movements. Two steps were taken in the following investigation: one to throw further light upon this problem of head movement, and the other to eliminate as fully as possible the effects of head movement. In the first place, in order that the exact amount of head movement might be measured, a fixed rod with points of reference quite independent of the head or camera was introduced into the field and photographed with the eye. By reference to this fixed rod it was always possible to determine when a head movement occurred. It was found that head movements occurred most noticeably just before long movements of the eyes. Due to the firm head rest used in our experiments the range of these head movements was never great. No movement was recorded of more than $0.5 \mathrm{~mm}$. If the eyes are looking at an external object which is fixed in its position, there can be very little doubt that there would be required even with a slight movement of half a millimeter, a compensatory eye movement in order to maintain fixation upon the object. These compensatory eye movements would lead to some confusion in the reading of the record. In order to eliminate any possible error from this source, it was possible, and indeed very easy in the investigation here reported, to so arrange that the object should move with the head. The result was that whenever the head moved in any direction the object was carried with it and there was no demand for compensatory eye movement. The objects at which the observers looked in this investigation consisted of two bright points mounted on a bamboo rod. The bamboo rod was held firmly between the teeth and supported at the extreme end on a bar across which it could very easily slide. This use of the teeth to hold the object of fixation involved the abandonment of the ordinary tooth-rest connected with the general head support. The head was supported from the side and back by means of adjustable rods fastened to the seat. Even with the removal of the tooth-rest the head movements, as noted above, were not very conspicuous, while the additional precaution taken in fixing the object to the head was sufficient 
to insure absolute freedom from error through head movement.

It may be well in this connection to call attention again to the advantage of one feature of the method which has been employed in all of the photographs taken in the Yale laboratory. The points of reference in all of these experiments have been attached to the head, so that when any head movement takes place, the eyes and the points of reference move together. It is only when the eyes move with reference to the head, therefore, that a record is produced in the photographs. Any method in which the measurements are made with reference to a fixed plate or other point of reference detached from the head will always lead to a confusion of head movements with movements of the eyes within the head. If movements of the eyes are measured with reference to a fixed plate and at the same time the object fixated is detached from the head, then any head movement for which there is at the same time a compensatory eye movement will result in a double error. First, there will be an error because of the movement of the head carrying the eyes into a new position with reference to the plate, and second, there will be an error which arises from a compensatory eye movement executed by the eyes in the maintenance of fixation upon the object of regard. The elimination of any possibility of confusing head movements with movements of the eyes in the head was secured from the very first by the method of attaching the points of reference to the head itself.

In his paper in the Psychological Bulletin of March, 1906, Professor Dodge (page 88) criticizes the use of points of fixation attached to the head on the ground that any head movement must first be measured by certain changes in the relation between the points of fixation, and must then be added as a correction to the records of the eye movements. The real significance of attaching the points of reference to the head seems to have escaped Professor Dodge entirely. The purpose is to prevent the head movement as measured with reference to a fixed plate from being confused with movements of the eyes in the head. These latter movements are the only movements of importance, unless we aim to distinguish between 
eye movements which are primary and eye movements which are compensatory. In order to meet Professor Dodge's criticism empirically a number of cases were examined in which there is a distinct record of head movement. The relation of the eyes to the points of fixation is shown in four distinct cases of this kind to be constant in spite of the movement of the head. This furnishes empirical justification for the method in answer to the purely theoretical calculations undertaken in the criticisms referred to.

Before reporting the results of the present series of photographs, it may be well to describe somewhat fully the meaning of the complicated figures which it is necessary to employ. The figures are complex because of the necessity of represent-
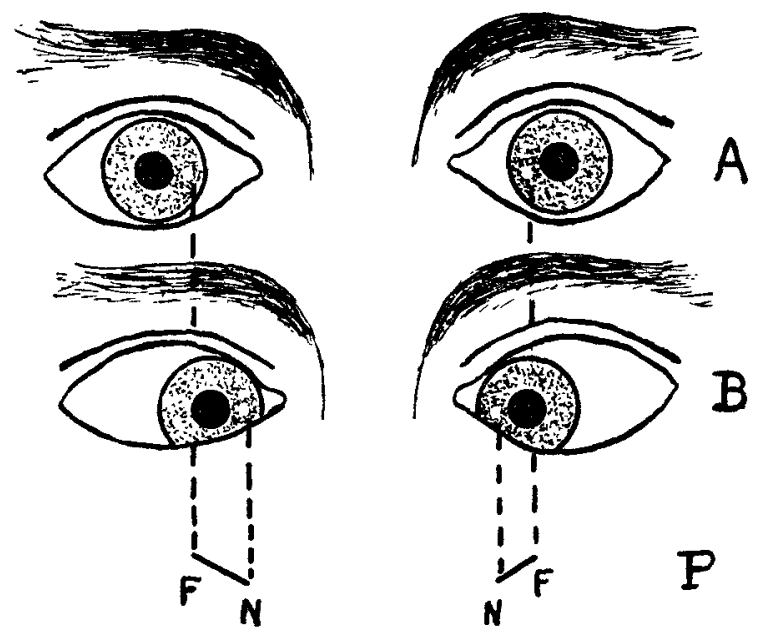

Fig. 98. In the two eyes $A$, fixation is at a point infinitely distant. In $B$ the eyes are shown converging on a near point. The convergence here represented is extreme. Th vertical dotted lines show projections of the 'white spot' to the lower part of the figure $P$. The positions $F, F$ show the projection of the non-convergent eyes. The downward slope of the lines $F N, F N$ indicate the downward movement of each eye in convergence. The positions $N, N$ are the projections of the convergent eyes.

ing in a single figure lateral movements and, where they exist, movements upward and downward in the vertical plane. The appearance of the eyes as they are shown in the photographs is schematically illustrated in Fig. 98. The irises are shown in 
similar setting of eyelids in two successive positions. These two positions can be projected as shown by the vertical lines and can be very fully represented by the lines $N F$ and $F N$. The line on the left indicates that the left eye has moved inward and downward, while the line on the right indicates that the right eye has moved downward and inward. The double movement of the two eyes constitutes a movement of convergence. If the two straight lines are read in the directions $N F$ and $N F$ they indicate a movement of divergence of the two eyes. Their downward slope indicates that in moving toward the nearer point the eyes not only converge laterally, but also moved downward. If a succession of such movements is to be indicated the successive backward and forward movements can be indicated by a succession of distinct lines placed vertically one under the other.

In the figures reported in this paper the successive lines indicating backward and forward movements are connected by means of dotted lines which are intended merely to show the relation between the end of a given movement and the beginning of the next successive movement. Thus, as will be seen by referring to Fig. 99, photographs $I-I O$ in the left-hand side of the figure were taken while the left eye remained fixed at a given point. Photograph I I showed a slight movement of the eye inward toward the nose in a horizontal line. Photograph $\mathrm{I} 2$ indicated a further movement in the same direction. The eye remained in this position while exposure 13 was being made. In photograph 14 the eye had reached a still further point of inward movement. At 15 it reached its extreme position of convergence and remained at this point up to and including photograph 2I. After photograph 2I, the eye made a slow divergent movement back to a position very near to that occupied in photograph I. This backward or divergent movement is indicated in the full-drawn line $2 \mathrm{I}-22-23-24$. The beginning of this line $2 \mathrm{I}-24$ is related to the end of the line I-I 5 by means of the vertical dotted line which shows the relative positions of the photographs taken during divergence as compared with those taken during convergence. The inward and outward movements represented on the left-hand side of 
the figure are for the left eye. They are directly related to the inward and outward movements represented on the righthand side of the figure for the right eye. It will here be seen that the right eye remains fixed in a given position during the first nine photographs. The right eye began its convergent movement somewhat earlier than the left eye, with the result that it reached the position marked Io while the left eye was still fixated at its original point. The right eye continued in this position during exposure No. I I. From I I-I 2 the right eye made the long movement of convergence by which it reached its final position of near fixation. This is indicated in the figure at the right by the completion of the line at $\mathrm{I} 2$. The right eye now remains fixed at the point 12 during the whole period of movement in the left eye from 12-15. At $2 \mathrm{I}$ the two eyes begin a movement of divergence which proceeds at about the same rate in the two eyes, as indicated by the line $2 \mathrm{I}-22-23^{-24}$ on the right. It should be noted again that the photographs in this paper report the results from one film only. If the second film taken with the one reported in Fig. 99 is drawn upon for results, it is found that the movement for the left eye from II-I 2 is a slow, continuous movement. This is indicated by the fact that the photograph on the second film which was taken between $\mathrm{I} I$ and $\mathrm{I} 2$ indicates that the eye occupied between II and I 2 a position midway between the points indicated in the figure here presented. The movement from $14-15$, on the other hand, is a much more rapid movement. After the exposure 14, there appears on the other film a photograph which shows that the eye moves rapidly to the position 15 and has reached that position before the photograph 15 represented in the figure is taken. In this way it is possible to interpolate between the photographs reported in the figures other photographs which shall increase the precision of time estimations. Thus the average time of the exposures represented in Fig. 99 is $94 \sigma$, while the time calculations can be made by interpolating the second film for periods of $47 \mathrm{\sigma}$. This $47^{\circ}$ can be relied upon in these photographs to be within a probable average error of $2 \sigma$; the time estimations are therefore fairly accurate and the inferences which will be based in 
this report on time relations will be restricted to those which are justified by periods of the length here under discussion.

The special problem taken up for investigation in the photographs to be reported in this series is the problem of simple movements of convergence and divergence between two fixed points. These points were placed directly in the median plane between the two eyes or brought into position directly in front of one or the other eye. In some cases the nearer point was somewhat lower than the more remote point, in others the converse relation obtained. The distance of the points was so arranged that the movements of convergence would be clearly marked. No effort was made to vary this distance through any long series of variations. Such additional measurements of different distances as well as other conditions of convergence are very desirable and will ultimately be undertaken. The range of the present investigations was determined by the necessity of solving first of all the definite though relatively simple problem of convergence and divergence within fixed limits. Five subjects were investigated in this series. Mr. Kerrigan and Mr. Cockayne gave a series each, showing the character of their convergent and divergent eye movements when the objects lie in the median plane between the two eyes. Dr. Cameron and the writer were photographed for a variety of different positions and under a number of different conditions. The fifth subject, Mr. G., was an extremely interesting subject for the particular investigation here in hand. Mr. G. is blind in the right eye and has been blind in that eye for a period of about fifteen years. He lost the sight of this eye in an accident when twelve years old. The blindness is due to opaqueness of the lens which was injured by accident. The subject can see vague images and recognizes at times when looking at a bright object that he has double images, especially when his eyes are fatigued. For the most part, however, he neglects entirely the images from the blind eye, these being in any case extremely vague and indefinite. Mr. G. was the subject in several series of photographs which will be reported in full in this paper.

In the course of this investigation it was possible inciden- 
tally to secure data on two minor problems which may be disposed of immediately since they are not of importance in the general report. First, in order to secure data on the amount of rotation which occurs during convergence and divergence, one of the subjects was photographed with two white spots on each cornea. When the eye moved in any direction these two spots made it easily possible to determine whether the movement of the whole eye was in the same direction or whether a movement of rotation took place in connection with the general movement of the eye. It was found in a number of cases that when the eye made a long movement of convergence or divergence, rotation factors were involved. In several cases when the eye moved in the convergent direction there was a tendency toward rotation in a clockwise direction through an angle amounting in some cases to $2^{\circ}$. The amount of rotation it will be seen from this statement was slight. Some effort to estimate the probable limits of error in the photographs indicated that the error in reading might amount to $30 \mathrm{~min}$. of arc. Furthermore, it was found that in all cases except one the rotation observed during the movement of convergence was corrected in the later phases of movement as the eye came to its position of final fixation. In the general movement of convergence with which we are concerned in the figures and in this report, rotation plays no appreciable part. The rotation seems to be a phase of movement proper during the adjustment rather than at its termination. Movements of rotation in divergence were also observed in several cases. These movements were both clockwise and anti-clockwise, there being three cases of the latter and two of the former observed in the course of these experiments. The range of these rotations is slightly greater than the range of rotation observed during movements of convergence. It amounted in one case to $3.5^{\circ}$, but was corrected during the last movement by which the eye came to its final position of fixation. This movement of rotation, which was the largest observed in the series, made a difference of less than one half a millimeter in the record as reported in the figures. It was, therefore, well within the probable error of the general observation reported and can be eliminated entirely 
from any consideration. The matter of rotation to be productively worked out will require much greater ranges of movement than those with which these results deal.

A second incidental matter to which reference may be made was observed in connection with one series of especially clear photographs in which the eyelid was shown with sufficient clearness in the photographs to be definitely measured in its position. The series of photographs in question involved a downward movement of the eyes during convergence, and it was observed that the downward movement of the eyes was in general accompanied by a downward movement of the eyelids. Indeed, it was clear in two cases that the downward movement of the lids preceded the downward movement of the eye itself. Photograph 42 in one case indicated a downward movement of the lid without any downward movement whatsoever of the eye itself; photograph 43 indicated the downward movement of the eye. The upward movements seemed to be somewhat more irregular in character. In one case a movement of the lid which was evidently a slight movement of winking occurred without any reference whatsoever to the eye movement and at a period when the eye was steadily fixating a single point.

Turning from these incidental matters to the main subject of the report, we may consider first four typical series from different subjects showing the character of the coördination movements when the points of fixation are in or near the median plane and at about the horizontal level of the eyes. Records of this sort are shown in Figs. 99-I02. All of these figures show that in converging and diverging upon a point of fixation the two eyes do not in most cases follow paths of the same form nor do they proceed with the same degree of rapidity. The lack of similarity in the motion of the two eyes is here very much more conspicuous than in any of the earlier series of photographs reported in No. I of the Yale Studies, where the eyes executed in all series merely lateral movements and did not change their degree of convergence or divergence. It was there noted in a number of instances that the two eyes do not follow exactly the same path or show the same rate of movement, but the incoördination was incidental in that case, in 
these results it is a very obvious and primary fact. For example, it will be seen on examining Fig. 99 that the left eye requires for the complete movement of convergence the first time it moves from the remote point to the nearer point a period of about $375 \sigma$, whereas the right eye of the same subject requires
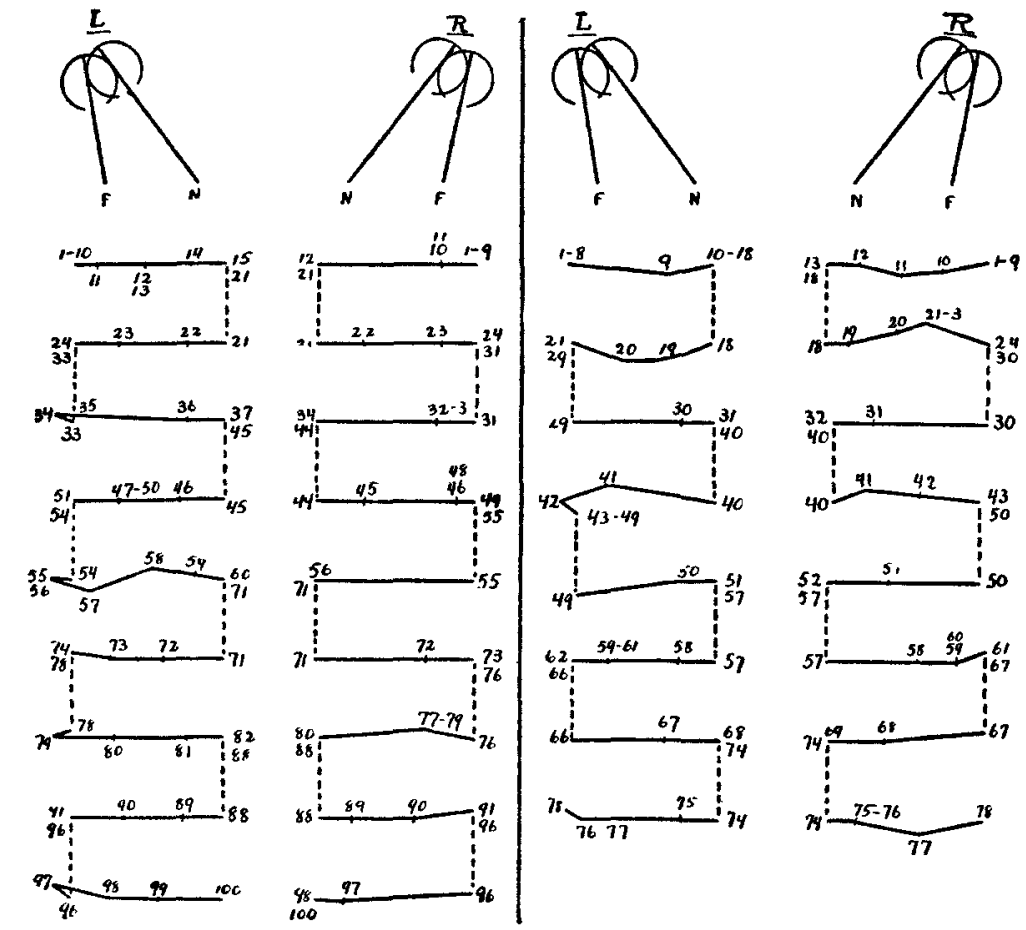

Frc. 99. Subject Mr. Kerrigan. Object of fixation two points, the more remote being at a distance of $55 \mathrm{~cm}$. from the bridge of the nose, the nearer at a distance of $30 \mathrm{~cm}$. The two points lie in the median plane between the two eyes. The average time of the exposure is $94^{\sigma}$. Individual exposures do not depart from this average by more than $3^{\sigma}$.

Fic. 100. Subject C. H. Judd. Points of fixation 30 and $55 \mathrm{~cm}$. respectively from the bridge of the nose. The two points do not lie in the median plane but are slightly foreshortened for the left eye so that movements of the right eye are greater in extent than those for the left eye. The average time of the exposure is $97^{\sigma}$ with a departure in individual determinations of not more than $3^{\sigma}$ from this average.

for its complete movement from the remote point to the near point somewhat less than $300 \sigma$. The difference is still more notable when we take the third movement of convergence. 
The left eye requires from photograph 54 , or at least from 56 to 60 , that is, four or six photographs, while the right eye in making the corresponding movement requires only the time elapsing between photographs $55-56$. The movement of the right eye in this case did not exceed $96 \sigma$, whereas the movement in the left eye certainly did not require less than $375 \sigma$, while if we count the lateral movement from 54-56 the time is nearer $550 \sigma$. Furthermore, the path of the eye movement in the two eyes is shown to be different in form by the lines extending in Fig. 99 from 56 to 60 . The same typical difference in the path of movement is seen by comparing the character of the movements of the two eyes between photographs 76 and 82 .

This lack of harmony in the two eyes has a special character in each one of the subjects. In Fig. 99 the left eye is in general behind the right eye in all of its adjustments. In Fig. Ioo, on the other hand, the right eye is slower in its adjustments than the left. The contrast in these two cases is very sharp. In Fig. Ior the right eye is again somewhat more rapid in its adjustments than the left eye, while in Fig. IO2 there is no marked superiority in speed of movement in either eye. If we attempt to throw further light upon this individual mode of convergence in which one eye often seems to be decidedly in the lead, we find no evidence which would go to show the relation of eye movements to right-handedness or left-handedness. The subjects of this experiment were right-handed, at least in the case of the three subjects represented in series 100-102. The subject of the photographs represented in Fig. 99 is not now accessible and the question did not arise in time to determine definitely whether or not he is right-handed. At all events, in the case of three subjects, all of whom are righthanded, there is a distinct difference in the behavior of the eyes. In the one case the left eye leads, in another the right, and in the third case there seems to be a balance between the two eyes. Nor is the eye which leads in speed of movement the eye which shows the greater acuteness of vision. The subject in Fig. I0o, whose left eye is decidedly in the lead, shows less acuity of vision for the left eye than for the right. The left eye of the 
subject represented in Fig. Ior is more acute in vision than the right eye, yet the left eye is slower in its adjustments. According to this very limited evidence, it would seem to be the less acute eye which makes the most rapid adjustments. The true explanation of the relation between left and right eyes is prob-

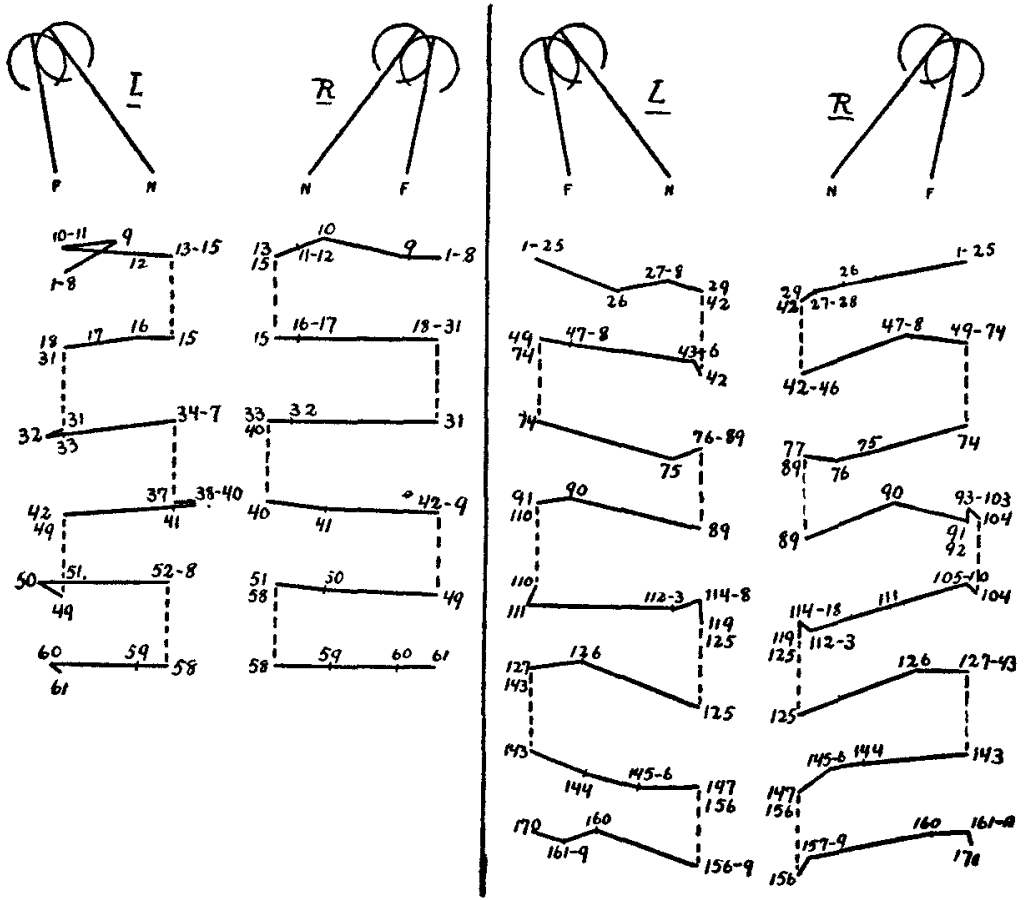

Fig. rox. Subject E. H. Cameron. Points of fixation 30 and $55 \mathrm{~cm}$. respectively from the bridge of the nose. The distance for the left eye is foreshortened. The average time of exposure is $117^{\sigma}$ with a possible variation in individual cases of $4^{\sigma}$.

Fig. roz. Subject C. A. Cockyane. Distance of points of fixation 30 and 55 cm. respectively. These points lie in the median plane between the two eyes. The nearer point is somewhat lower than the more remote point with the result that the eyes in converging move downward and in diverging move upward. The average time of exposure is roo $\sigma$ with a variation not exceeding $3^{\sigma}$ in individual cases.

ably to be sought in the fact that there is a difference in muscular balance in the two eyes. The fact that there is a general agreement in character of movement among the four subjects, while at the same time the subjects differ from each other radically in the matter of relation between the two eyes, would 
seem to indicate that the relation between the two eyes is a wholly incidental matter. It is not essential to the consideration of binocular adjustment as is shown in Fig. 102, which is a case of almost equal balance of the two eyes. Furthermore, the special characteristics of movement in one eye or the other are more marked in general in the horizontal plane which is represented in Figs. 99-102 than in other planes. Series of photographs were taken with the subjects represented in Figs. 100 and IOI, with the points of fixation placed at various angles out of the horizontal. Positions of $40^{\circ}$ below the horizontal plane, of $15^{\circ}$ below this plane, of $15^{\circ}$ and $30^{\circ}$ above were taken with each of the subjects. One of these records is reproduced for another purpose in Fig. II4. It is typical in that it shows the same general form of movement as in the horizontal. It may be stated, however, that in general extreme positions above or below tend to induce change in the relations between the eyes. Thus for the subject of Fig. Ioo there is a mere uniform balancing of the movements in the two eyes than that represented in Fig. Ioo for all upward movements. Otherwise the characteristics of the figures are essentially the same. This would seem to indicate as held above that differences in muscular tension are the significant factors in determining the relation of the eyes. When the eyes are tuined upward the tensions are not the same as when the eyes move in a horizontal plane. Furthermore, when the balance of tension is entirely changed by bringing the objects into line with one of the eyes, the relation of the eye thus relieved of tensions of its own, to the other eye, is very marked. Cases of this kind will be discussed fully in a later paragraph and are exhibited in Fig. I03. We may sum up this part of the discussion, therefore, in the statement that the two eyes do not move to points of convergence or divergence at the same rate for most subjects nor always in similar paths, but that this lack of similarity in the movements of the two eyes is probably due to external muscular causes and not to internal nervous adjustments.

It is important to notice in connection with the recorded disparity between the movements of the two eyes that fixation is not completed for the subject's inspection until such time as 
the slower eye has reached its final fixation upon the point to which attention is given. Evidence on this point was collected in the course of the experiment by giving the subject a reaction key and requiring him to press down upon the key as soon as he was satisfied that he had fixated the point nearer at hand. He continued the pressure on the key until such time as he executed a movement of divergence when he released the key. The record made by pressing and releasing the key was taken through a marker on the same strip of smoked paper as the record showing the rate of the photographs. In this way the subject's introspections with regard to his convergence and divergence were taken in parallel with the photographs showing the position of the eyes. Referring to Fig. Ior, for example, the subject's reaction record shows that he was satisfied that he was looking at the near point when photograph I 4 was taken. $\mathrm{He}$ was satisfied again that he was looking at the more remote point at photograph 20. The following introspections show the near point at photograph 34; remote point photograph 44; near point again at photograph 52 ; remote point at photograph 63. In all of these cases it will be observed that the reaction is slower than the final adjustment of convergence or divergence by enough to allow in each case for the reaction time of the hand after fixation had been completed. In no case does the subject make the introspective reaction before the movement of convergence or divergence of both eyes has been completed. This is typical of the introspections of all the subjects. Records of introspections were taken with the great majority of the records upon which this paper is based and there is no case in which the introspective record does not bear out this general statement.

A second general characteristic of all the movements shown in Figs. 99-100, and the other similar records mentioned above, appears in the fact that the time of convergent and divergent adjustment is relatively very long. For comparative results which do not involve convergence and divergence, reference may be made to certain photographs that will be reported in the present series and are represented in Figs. II 7 and 118 of this paper. It will here be seen that the first two movements 
in Fig. I 7 required certainly not more than I $80 \sigma$ each, and the second movement which lies between photographs I $_{2}$ and I 3 could not have required more than $90 \sigma$. Similar evidence can be drawn from many of the earlier series reported in the first number of the Studies. The movements of convergence and divergence as contrasted with these simple lateral movements required a period of time which is in general $350 \sigma$ or more. Furthermore, the movements of convergence and divergence here represented show themselves to be complex and difficult in the frequent pauses which are made by the one eye or the other in passing from one point of fixation to the other. It is obvious that we have to deal here with a complex form of adjustment. This general fact can not be explained as could the lack of uniformity in the movement of the two eyes, by any reference to the external muscular structure of the eyes. The eyes are converged or diverged in such a way as to fixate definite points, and these movements involve a careful adjustment with many pauses and corrective movements which consume the long period of time required for this adjustment. The evidence is not wanting that the movements are in many cases movements of fine adjustment after the main movement has been executed. For example, in Fig. I02 movements of the left eye between 28 and 29 , between 75 and 76 , between II $_{3}$ and II 4 are all of them obviously in the nature of final corrective movements. Other examples of similar character can be seen in all of the figures. This final adjustment of the eye would seem to signify that the complete execution of a movement of convergence or divergence is in the nature of a slow and careful adjustment of the eye to a stimulus which is in some form or other recognized as not completely met by the main movements. We shall call attention in the later discussion to other evidences which go to show that the movement of convergence is under the constant direction of the stimulus and is a movement of fine and difficult adjustment.

A third fact which may be noted in certain of these figures now under discussion, but which will be very much more fully illustrated in later figures, is the fact that in some cases the eyes before they begin the careful adjustment of convergence, exe- 
cute a lateral movement in which the two eyes sympathize by moving in the same direction rather than in opposite directions as required for convergence or divergence. A conspicuous illustration of this is to be found in Fig. IOI in the movement between photographs $3 \mathrm{I}$ and 32 . After photograph $3 \mathrm{I}$ the right eye moves in a long sweep toward the left, thus reaching a position required for convergence. The left eye, on the other hand, instead of moving in such a way as to converge upon the nearer point, executes like the right eye a movement from right to left. This movement is directly opposed to the movement of convergence which must later be executed by this eye and it is explicable only by assuming that the left eye sympathizes automatically in its behavior with the stronger impulse of the right eye. A similar fact may be seen in Fig. 99 in the movement which lies between photographs 96 and 97 . Here again the right eye executes a long movement toward the left and the left eye follows in the same direction. The tendency for the two eyes to move in the same lateral direction at the same time, rather than in the direction of convergence or divergence, seems, therefore, even in these earlier photographs to be sufficiently strong to assert itself with all clearness.

Stronger evidence of the fundamental character of this tendency to move the two eyes in the same direction comes out in a number of series of photographs taken with the objects of fixation so arranged that they lay directly in the axis of vision of one of the eyes. Two series of photographs of this kind are shown in Figs. IO3 and I04. These photographs are from the subject reported also in Fig. IOI. In Fig. IO3 the left eye is obliged to make a movement toward the right whenever it changes its center of fixation from the remote object to the nearer object. The right eye, on the other hand, is not called upon to change its line of regard in looking from the remote object to the near object, it simply changes the degree of accommodation of the lens when it has finally reached its position of rest. It is a very striking fact that the process of adjustment in the right eye which is called upon to maintain a single line of regard, is quite as complex as the process of adjustment in the left eye which is required to make large movements of con- 
vergence and divergence. Indeed, in some respects it is even more complex, and this complexity can be described very simply by the statement that whenever the left eye makes a movement of convergence or divergence there is a tendency for the right eye to follow the same path of movement as the left eye. Thus, when the left eye moves toward the right between photo-
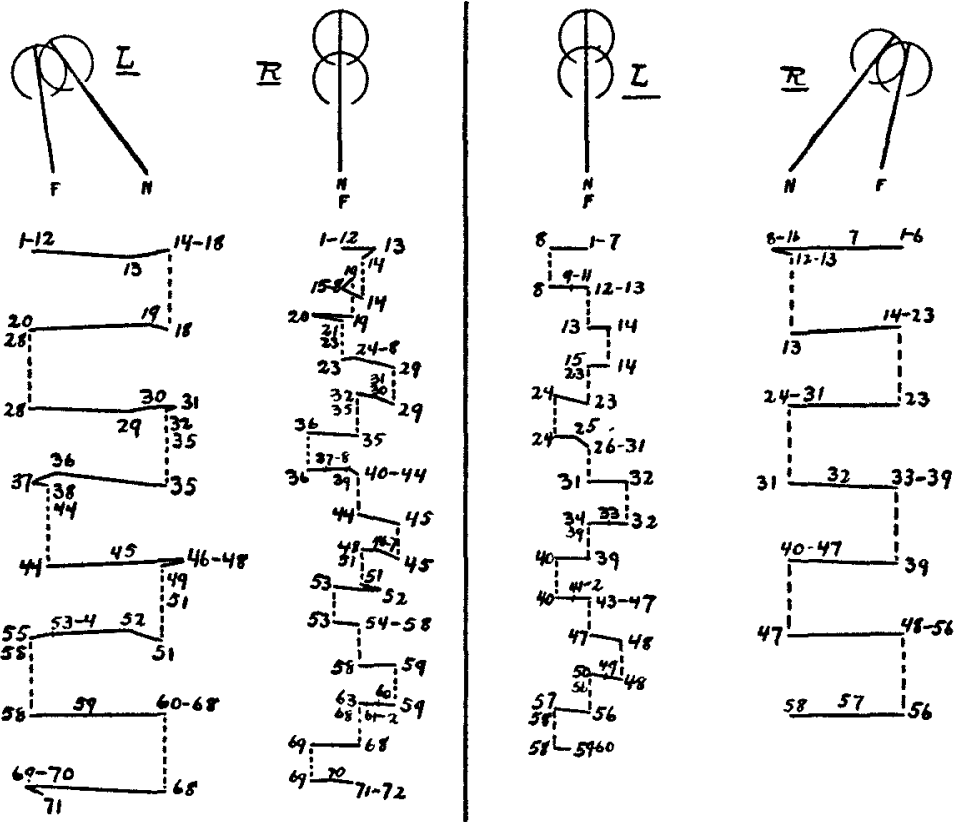

Fig. 103. Subject E. H. Cameron. The objects of fixation at 30 and $55 \mathrm{~cm}$. respectively from the bridge of the nose. These points lie in the line directly in front of the right eye so that the right eye in fixating the two points is not required to move its axis laterally. The average time of exposure is $120 \%$ with a possible deviation in individual cases of $4^{\sigma}$.

Fic. I04. Subject and conditions like those in Fig. ro3 except that the two points of fixation here lie in the line directly in front of the left eye. Average time of exposure $124^{\sigma}$ with a possible deviation in individual cases of $4^{\sigma}$.

graphs ${ }_{2} 2$ and I $_{3}$ the right eye also makes a movement toward the right. This movement of the right eye brings it out of line with the two points of fixation. There follow, therefore, a series of movements of readjustment, as indicated in the figure, until in photograph i 5 a final fixation is reached satisfactory to the subject. It is interesting to note in this connection that the introspection of the subject showed that he regarded 
the fixation as complete only after photograph i 5 . Continuing in the detailed examination of Fig. IO3, we find that after fixating the near point for a period of time the two eyes between photographs 18 and 19 execute a slight movement of divergence. This movement of divergence showed itself in both eyes. This and other evidences throughout the figures seem to show that divergence is simpler than convergence. But even divergence gives way before the strong tendency to complete sympathy in lateral movement. In the case in hand, divergence is evidently only preliminary to the further adjustment, for there follow from 19 to 20 two like or sympathetic movements in the two eyes, both of them moving toward the extreme left. The right eye is involved by this sympathetic movement in the necessity of a secondary readjustment which is not fully accomplished until photograph $2 \mathrm{I}$. The introspective record shows that the subject's reaction for divergence parallels the $23 \mathrm{~d}$ photograph. Between 28 and 29 there is another sympathetic movement between the two eyes. The readjustments which take place from 29 to 32 evidently involve a different type of the sympathetic relation between the two eyes. The right eye is involved in the necessity of moving from 3 I to 32 in order to regain the natural position of fixation upon the near point. The left eye seems also to have overshot the mark of fixation between $3^{\circ}$ and $3^{I}$. It is consequently involved in a movement of readjustment. Another case of this kind of correction for the left eye seems to appear between 48 and 49 .

It will be remembered that the subject of these photographs in Fig. ${ }^{0} 3$ showed a natural tendency, as shown in Fig. 99, to make more rapid and independent movements with the right eye than with the left. The strong sympathetic behavior of the right eye with the left, as reported in this series of photographs in Fig. IO3, is a clear indication of the fundamental and natural character of the sympathetic movement of the two eyes. The fact of sympathetic movement appears in the reverse relation in the photographs reported in Fig. I04. Here, again, the eye which is not called upon by the conditions of the experiment to execute any lateral movements, that is, in this case the 
left eye is constantly involved in sympathetic adjustments in which it moves at first in the same direction as the right eye and then afterwards by a series of readjustments comes back
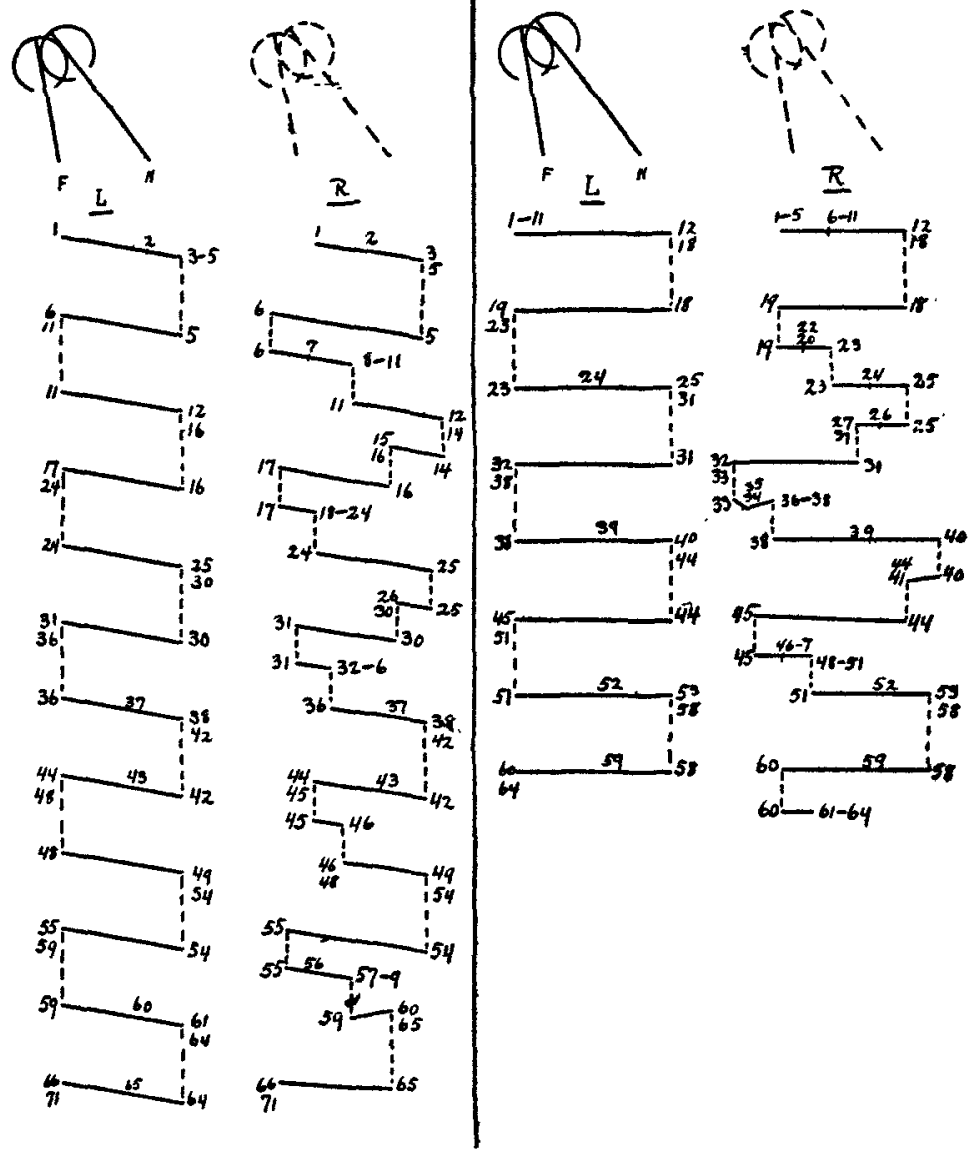

Frc. ro5. Subject Mr. G. who has been for a period of years blind in the right eye. Points of fixation 50 and $25 \mathrm{~cm}$. respectively in the median plane between the two eyes. The near point somewhat lower than the more remote point. Average time of exposure $104^{\sigma}$ with a possible deviation in individual cases of $3^{\sigma}$.

FIG. ro6. Subject same as in Fig. r05. Points of fixation 50 and $25 \mathrm{~cm}$. respectively from the bridge of the nose in the primary horizontal plane. Average time of exposure $82 \sigma$ with a possible deviation in individual cases of $3^{\sigma}$.

to the original point of fixation. Series of exactly the same type as here obtained were secured from the subject reported 
in Fig. Ioo. The general statement here worked out in detail is also supported by earlier observations. Professor Dodge in an earlier paper on eye movements ${ }^{1}$ referred to facts of the same sort as here described.

Further evidence of the fundamental character of this sympathetic movement of the two eyes was obtained from subject G., who, as was noted above, has been for a long period blind in one eye. Figs. I05 and 106 represent two series of photographs from this subject. It will be seen from the examination of these figures that the right eye, which is blind, does not make movements of convergence or divergence as its primary movements in any case. The first movement of the right eye always consists in a distinct and extensive movement in the same direction as the left eye. For example, between photographs I I and I 2 the left eye makes a long movement from the far point to the near point. The right eye makes a movement of about the same extent in the same direction. Not only is the lateral movement in this case in the same direction, but the movement of the right eye is downward in keeping with the movement of the left eye. After a short interval the right eye, as seen in the line between photographs $\mathrm{I}_{4}$ and I 5 , changes its position in such a way as to come back somewhat toward its original position in photograph I I. This it will be noticed is not a movement of convergence in any proper sense of the word, it is rather a tendency to readjust the position of the right eye so that it shall keep its original position before it made a movement in sympathy with the left eye. In like manner, when the left eye makes a movement of adjustment from the near point to the more remote point, as indicated in the line I 6-I 7 , the blind eye makes a similar movement. It later corrects this long sympathetic movement between 16 and 17 by a short movement of readjustment between 17 and 18 , but here again the position 18 is not the same as the original position I 6 from which it started. The final position of the right eye at any given moment seems to be more or less the accidental resultant of the accumulated tendencies of earlier sympathetic movements. The movements of the blind eye are, however,

'A merican Journal of Physiology, 1903, VIII., p. 328. 
very clearly sympathetic movements and not movements of an independent character. The same facts appear in Fig. Io6, where the blind eye shows even a more marked tendency to sympathize with the left eye. The left eye in this case executes a somewhat longer movement than in Fig. 105 and the result appears in the very long sympathetic movements in the blind eye. This is notably true between photographs $3 \mathrm{I}$ and 32 , between photographs 38 and 40 , and between photographs 44 and 45 .

It is important to note in connection with these photographs of subject $G$. that the whole activity of convergence and divergence is reduced to a very much simpler level when it is a monocular adjustment. This is evidenced not only by the photographs exhibited in the figures, but also by the introspective testimony which was taken in parallel with the photographs. Thus, the subject reacted for complete convergence in parallel with photograph 4. Divergence was shown in parallel with photograph 7. The next convergence falls upon photograph 12 , divergence on 18 , convergence on 26 , divergence on 33 , convergence on 38 , and so on through the series. It thus appears that the convergence and divergence of the subject who sees with one eye only are free from the delays which are required in the case of subjects who see binocularly, and the form of movement is at the same time very much simpler in character. There seems to be, therefore, clear evidence not only that the lateral movement is the simpler form of united action of the two eyes, but that when lateral movement is the only form of movement required the whole adjustment is simple in its character.

Further evidence with regard to the simplicity of mere lateral movement is to be derived by an examination of monocular convergence and divergence, as shown by normal subjects when a single eye has been covered up. Figs. 107 and 108 show two simple cases of convergence and divergence after covering one eye. These photographs are from the subject reported in Fig. IOO, and a comparison of these figures with the results in Fig. IOo show immediately the much simpler character of the movements. The time required for the monocular adjust- 
ments is relatively shorter. For example, in one case between photographs 37 and 38 , the whole movement is executed in a period of time considerably less than roo $\sigma$. By referring to the second film it was found that the eye had reached the position indicated in the figure by 38 at the time when the photograph was being taken which lies between 37 and 38 . In other words, the total movement from 37 to 38 as a movement involved between 45 and $90 \sigma$. The adjustment between 49

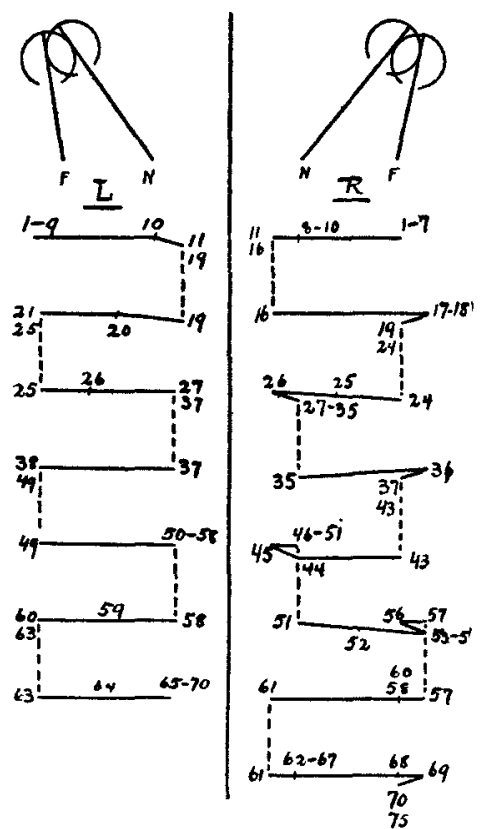

FIG. 107. Subject C. H. Judd. Points of fixation 55 and $30 \mathrm{~cm}$. respectively from the eye and in a line directly in front of the nose. The right eye is entirely covered. All movements recorded in the figure are accordingly for the left eye. The average time of exposure is $94^{\sigma}$ with a variation not exceeding $3^{\sigma}$ for individual exposures.

Fic. ro8. Subject and conditions same as for Fig. ro7 with the exception that the left eye is covered and movements here recorded are for the right eye. Average time of exposure $90 \sigma$ with a possible deviation of $2^{\sigma} \sigma$ from the average.

and 50 was also sufficiently rapid so that its period can be described as distinctly below $100 \sigma$. The introspective records of the subject show that complete divergence and convergence was secured in these two cases in parallel with the next succeeding photograph, as in most of the earlier records. There 
is, therefore, obviously no delay such as is demanded in binocular convergence and divergence.

The movements of the eye in Fig. I08 show certain distinct complexities in character. These complexities may be described by the statement that when the eye is moving in a given direction there is a tendency for it to move too far in the direction in which it is traveling. Thus, between 16 and 17 in Fig. I 88 there seents to be so long a movement that there is necessity for a readjustment as indicated between 18 and 19. Similar facts are shown in the readjustments between 26 and 27 , between 36 and 37 , between 45 and 46 , between 69 and 70 , and a very complicated readjustment appears between 55 and 57. The meaning of these readjustments in monocular convergence and divergence is not easy to make out. Evidently the right eye in this subject is less regular in its behavior than the left eye. This may be related to the fact that the right eye shows greater irregularity of movement in the earlier series in which both eyes are involved. The right eye in this subject, as stated above, is the eye which shows the greatest acuity of vision. It is, therefore, improbable that its less precise adjustments at the end of the movement are due to retinal conditions. It is probably true that the muscular balance of the two eyes is not the same and it is not unlikely that the pecularities of behavior are connected with these muscular inequalities rather than with the internal or retinal processes.

Collateral evidence in view of this conclusion can be offered in the case of the subject of these photographs by means of experiments discussed by the writer in a paper published in Science, I 898, VII., pp. 269-27 I. The experiments in question may be tried by covering one eye and steadily fixating a bright object with the uncovered eye. The covered eye should now be suddenly uncovered when there will appear double images which are crossed and therefore indicate that the center upon which the lines of regard of the two eyes were converged was more remote than the object fixated by the open eye. The position assumed by the eye which has been covered in this case will undoubtedly depend in part upon its own tendencies of relaxation. That the center of convergence is further than 
the point of fixation would indicate that the natural tendency of relaxation in the covered eye is in the direction of a movement of divergence. The distance of the double images from each other at the moment of uncovering the eye will give some clue to the degree of divergent tendency in the covered eye. The observation of this double image requires some practice. The writer has made long series of observations with his two eyes and finds that the distance between the after-images when the right eye is covered is greater than the distance when the left eye is covered. The muscular tensions of the right eye seem from this experiment, therefore, to be somewhat more pronounced than the muscular tensions of the left eye. This result is clearly in agreement with the typical differences in the behavior of the two eyes, as shown in the photographs exhibited in Figs. 107 and 108 . That the right eye should be for this subject more difficult to bring into binocular convergence and divergence, as is shown in Fig. Ioo, seems also to be clearly in agreement with these evidences regarding the monocular behavior of the right eye. Such considerations show the difference between binocular and monocular adjustments and at the same time show also their intimate interrelation. Monocular peculiarities constitute the negative tendencies which must be overcome in order that binocular adjustments may be accomplished. Binocular adjustment is therefore a complex process in which monocular tendencies and tendencies toward lateral sympathetic movements must be replaced by a more elaborate form of coördination.

The simplicity of adjustment in monocular vision can be further attested by means of the series of photographs from another subject, as reported in Figs. Iog and I Io. In these two series the camera was set in motion before the eye which was not to be used in the full series was covered. The result is that the first movements are binocular. The binocular movements here reported did not continue long enough to give very full evidence, but the second binocular movement in Fig. Io9 agrees with all the other records from this subject, as for example, those reported in Fig. I I. In considering the first movements in Figs. IO9 and I 10 it should be recognized that the first 
movement often differs from the later movements. At all events there can be no ambiguity regarding the character of the monocular movements of this subject. Though they consist of adjustments to near and remote points they are ex-

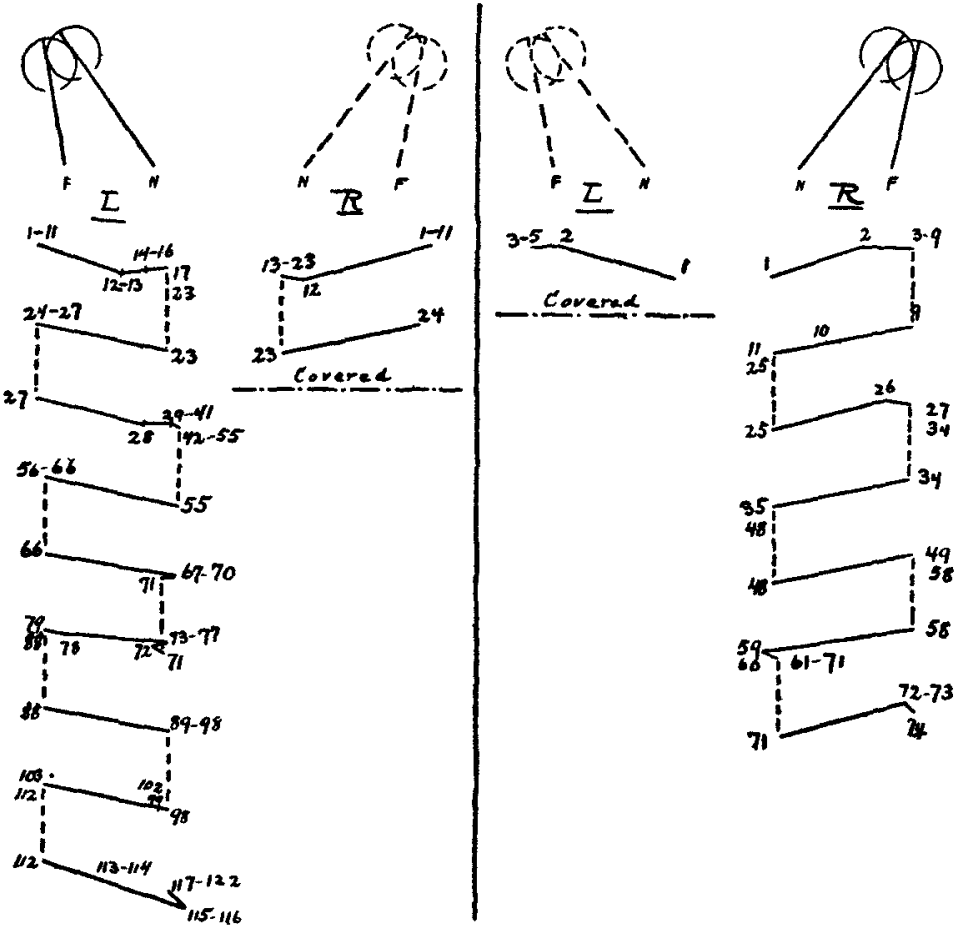

FIG. 109. Subject E. H. Cameron. Points of fixation 55 and $30 \mathrm{~cm}$. respectively in the median plane between the two eyes. The axes of vision are directed upward in looking at the more remote point and somewhat lower in looking at the near point. After twenty-six exposures the right eye was covered so that the remainder of the record shows the movement of the left eye only. The average time of exposures $75^{\sigma}$ with a possible deviation in individual cases of $2 \sigma$.

FIG. IIO. Subject and conditions the same as Fig. Io9 with the exception that the left eye was covered in this case as indicated in the figure after five exposures. Average time of exposures $75^{\sigma}$ with a possible deviation in individual cases of $2 \sigma$.

tremely simple and in striking contrast with the binocular adjustments of the same subject as reported in Figs. IO I and I 14. One special case of monocular adjustment which is of cru. cial importance for experimentation with monocular vision may 
be investigated by the methods here employed. If two points are placed in a direct line in front of one eye, and the second eye is covered so as to be entirely excluded from participation in vision so far as retinal factors are concerned, it is found that the open eye is involved in certain adjustments which suggest
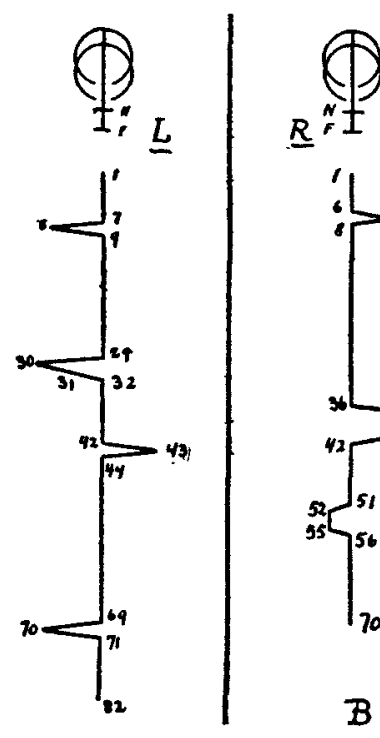

A

Fig. IIx. Subject C. H. Judd. This figure represents the eye movements by a different method from that adopted in the earlier figures. The vertical length of the line indicates the number of exposures. Thus, in $A$ the distance from the beginning of the line to the movement which is indicated at 7 is on the same scale as the distance from 9 to 29 which represents a continuous fixation of the eye at one point during 21 exposures. Slight movements of the eye about the point of fixation are neglected in this figure. $A$ indicates the form of motion for the left eye, $B$ the form of motion for the right eye when the two points of fixation lie in the direct line of the visual axis of the open eye, the right eye being covered while the photographs were being taken for the left eye, and the left eye being covered while the photographs were being taken for the right eye. The average time of exposure for both $A$ and $B$ was $96 \sigma$ with a possible variation in individual cases of 20 .

the continued participation of the covered eye in the movement of convergence and divergence. The conditions here under discussion are related to those which are presented in Figs. IO3 and 104. It was there found that the eye which was not required to make any lateral movement in fixating near and remote 
points did, nevertheless, by virtue of its sympathetic relation with the eye that was involved in elaborate lateral movements, execute certain unnecessary sympathetic movements and certain supplementary movements of readjustment. In Fig. I I I two series of photographs are reported which deal with this case which has often been assumed by experimenters to be a case of pure monocular vision. In the series of photographs represented in $A$ the right eye was entirely covered and the points for fixation were so arranged as to lie directly in front of the left eye. The introspections of the subject show that at a point corresponding to photograph io the subject was satisfied that he had fixated the nearer point. The fixation of the nearer point called for no movement whatsoever of the left eye. The two movements which lie between 7,8 and 9 must, therefore, be explained as a sympathetic movement and a movement of readjustment. The right eye which was in this case entirely covered up undoubtedly made some movement. That the covered eye does not cease its movements in binocular adjustments can easily be demonstrated by laying the finger lightly on the lid of a closed eye and observing the movement of the closed eye when the open eye changes its fixation from a remote to a near point or the converse. The normal subject who makes this observation will discover that the closed eye tends to converge and diverge not as in the case of the blind subject reported in Figs. 105 and 106, but rather in a way similar to that reported in Figs. I03 and 104. In the case in hand the covered right eye undoubtedly executed a movement from right to left while the left eye was making its movement in the same direction from 7 to 8 . The left eye then made a rapid adjustment from 8 to 9 , while the right eye continued its movement of convergence.

A similar case appears in the figure in the movement and adjustment between 29 and 32 . Here the subject's introspections show that the satisfactory fixation of the near point coincides with photograph 32. A sympathetic movement of divergence with the corresponding introspective evidence appears between 42 and 44 . These photographs show with all clearness that the covered eye is by no means eliminated from con- 
sideration when an adjustment from a remote to a near point is under discussion. These facts constitute a fatal objection to the methods and results which have become classic in psychology for experimentation on monocular accommodation. Among recent investigators, Arrer, Hillebrandt, Baird and others have placed the objects of fixation exactly as they were placed in this series of photographs in a direct line in front of the open eye. They have covered or closed the other eye and proceeded with their investigation on the assumption that they had eliminated binocular influences, at least in major part. All that they have eliminated in such cases are the retinal images involved. There is a very large influence, as shown in these photographs, so far as the movements of convergence and divergence are concerned. Furthermore, the effects on the behavior of the open eye are by no means uniform either in character or in mode of occurrence. For example, it is seen in Fig. I I by contrasting the behavior of the right and left eyes of the same subject under similar conditions, first, that the movements of the left eye are more extensive than those of the right eye, while adjustments are in general very much more rapid. The readjustments in the case of the right eye are so slow that in some cases, as for example between 36 and 42 , a period comparable to the period ordinarily required for convergence is involved. That different subjects would probably differ in the extent to which the closed eye influenced the open eye is indirectly evidenced by the fact that the blind subject in whom one eye had long been disused made very irregular movements with what in his case corresponded to the covered eye. In his case the blind eye was almost completely dominated by the tendencies of movement in the normal eye. It is probably true in certain subjects that one eye is much more independent than in others. There may be individuals for whom the control of normal vision is sufficiently strong to dominate the whole movement. Indeed, there were in the case reported in Fig. I I I, between photograph 8 and photograph 36, three movements, two of divergence and one of convergence, for which there is absolutely no evidence of any readjustment in the open eye. This itself is sufficient evidence that the influ- 
ence of the covered eye is somewhat irregular in character. In some cases apparently the open eye dominates, in others there is a clear domination of the covered eye. The net result is that the binocular influence not only is not withdrawn, but it is complicated in an unknown fashion by the various tendencies
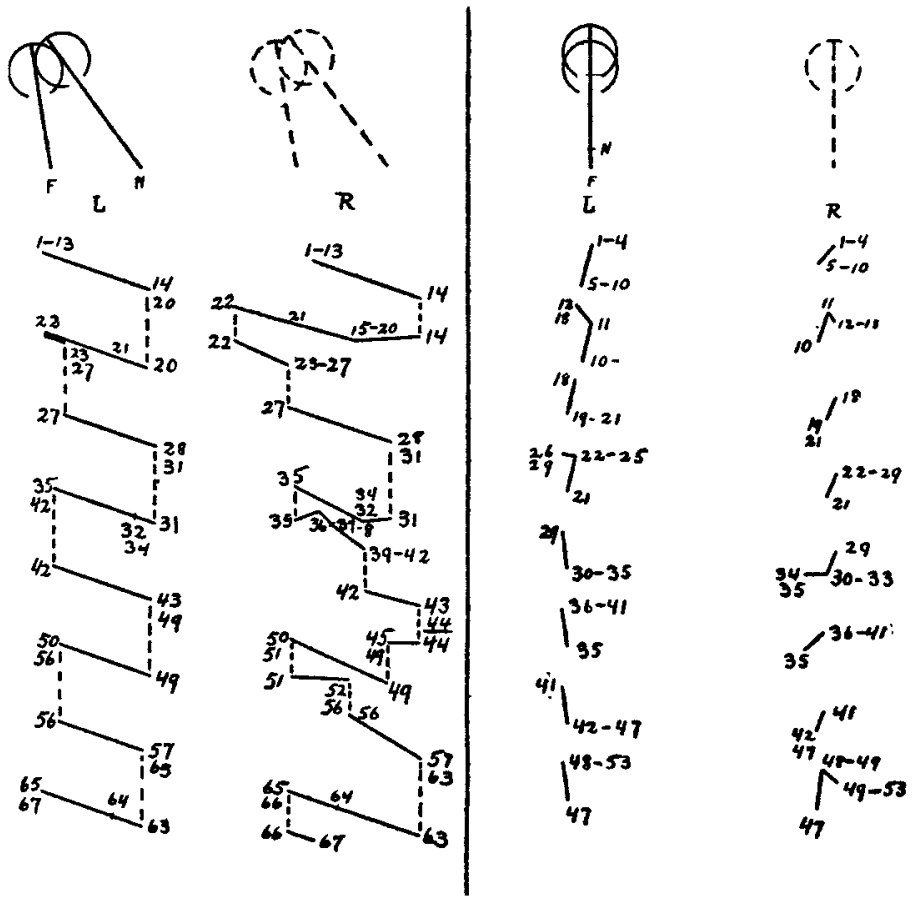

Fig. 112. Subject same as in Fig. 105. Distance of points from the eye so and $25 \mathrm{~cm}$. respectively. Points placed in a line directly in front of the right eye such that if the eye were capable of vision the points would lie in the line of fixation of the right eye. Average time of exposures $73^{\sigma}$ with a possible deviation in individual cases of $3^{\sigma}$.

Fig. 113. Subject as in Fig. 105. Points of fixation 50 and $25 \mathrm{~cm}$. respectively in front of the bridge of the nose. These points were placed in the line of fixation of the left eye. Average time of exposures $76^{\sigma}$ with a possible deviation in individual cases of $3^{\sigma}$.

which produce in the open eye movements which are wholly uncalled for by the demands made upon that eye considered by itself. The reason why no conclusive evidence as to the character of monocular vision has ever been derived from the experiments of Arrer, Hillebrandt and others becomes per- 
fectly obvious in the presence of these facts. If any method of experimentation with monocular vision is ever to be devised it must be recognized as a fundamental fact that monocular vision is not produced by simply covering one eye.

In order to test this matter with the blind subject, the conditions were so arranged in the series of photographs reported in Figs. I 2 and I I 3 that in the one case the points of fixation were placed in a direct line in front of the blind eye, in the second case the points of fixation were placed in a direct line in front of the normal eye. Unfortunately in both cases the nearer point was placed somewhat lower down than the more remote point, with the result that an adjustment upward and downward was involved in the change of fixation between the points. The overwhelming importance of the normal eye is clearly attested in Fig. 112 . There is one interesting case in which movement 22-23 seems to show some lingering influence of the blind eye. In moving from 21 to 22 there seems to be an excessive movement in the case of both eyes. The recovery in the same direction in both eyes seems to follow in 22 to 23 . Whether this is a mere accident of adjustment in the left eye or a direct case of relationship of movement in the two eyes is, of course, impossible to say; it is certainly not a typical fact, for it does not appear in the other parts of the series.

In Fig. I I 3 there is exhibited up to photograph 30 a close sympathy between the two eyes. There is one exception to this sympathy, namely, between II and I2, where the blind eye moves downward at the same time that the normal eye moves upward. There is also a readjustment in the normal eye between 25 and 26 , after which there seems to be a great uniformity in the behavior of the normal eye. This uniformity in behavior of the normal eye follows upon a series of readjustments prior to photograph 26 , which readjustment may indicate that the subject was selecting the method of fixating the objects at which he was to look. At all events there is a difference between the adjustments above photograph 26 and below. There is in the series of photographs for the blind eye also a radical readjustment between 30 and 34 . This readjustment seems to have no related fact in the behavior of 
the normal eye. Furthermore, the activity of the blind eye never becomes, as does the activity of the normal eye, regular in direction and extent. There is the greatest possible irregularity exhibited in the case of the blind eye. If these photographs justify any conclusion with regard to normal vision, those conclusions seem to be in support of the general conten-

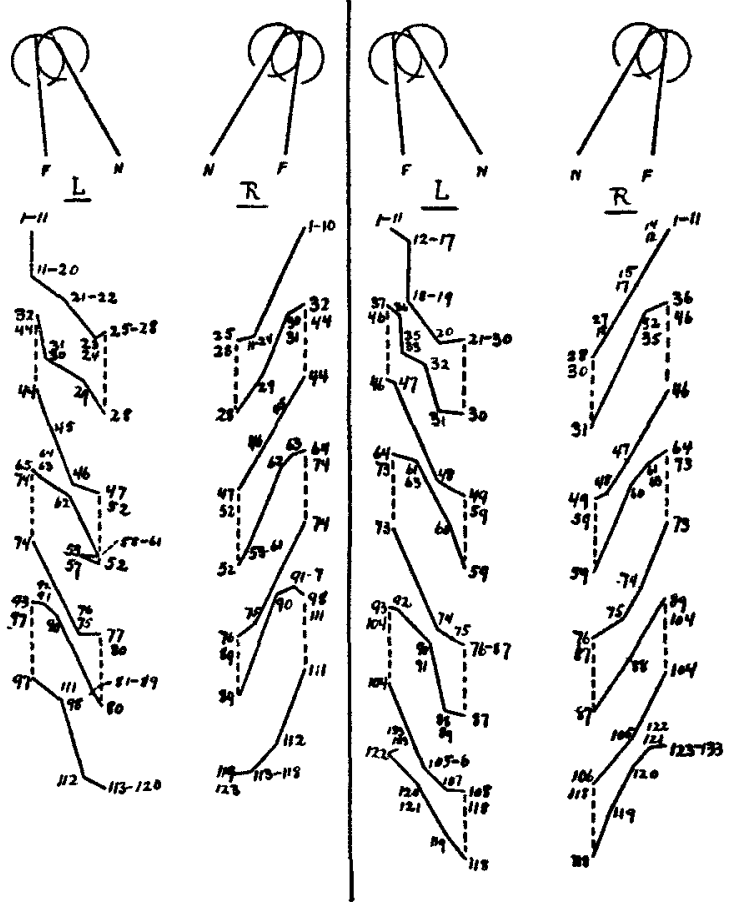

FIG. II. Subject E. H. Cameron. Points of fixation 55 and $30 \mathrm{~cm}$. from the bridge of the nose, the more remote point being much higher than the nearer point. Average time of exposures $73^{\sigma}$ with a possible deviation in individual cases of $2 \sigma$.

Fic. Ir5. Subject and conditions the same as in Fig. 1r4. The series of photographs here reported were taken one year and three months later than the photographs reported in Fig. . The average time is $75^{\sigma}$ with a possible deviation in individual cases of $2 \sigma$.

tion that the eye which is not guided in its behavior by retinal images is extremely irregular in its activities. So far as the criticism of the methods of monocular experimentation are concerned this figure supports the general contention that the influence of the closed eye is extremely irregular. 
Returning from the discussion of monocular movements to other cases of binocular adjustment, Figs. I I 4 and I 15 report in detail the results of two series of photographs in which the convergence on the near point was accompanied by a very pronounced downward movement of the eyes. It will be seen by examining these figures that the adjustments were fairly well balanced on the two sides in point of time, although in general as in the earlier series for this subject the right eye is somewhat more rapid in its adjustments than the left. This appears in Fig. II 4 in the movement between 74 and 77 and in Fig. I I 5 in the movements between 87 and 93, and 104 and 108 . There are, however, one or two cases in which the left eye seems to be somewhat in advance. The series are reported here not so much for the sake of reiterating the statements made in the series reported in Fig. IOI, as rather for the sake of calling attention to certain characteristics of the eye movements which show the difficulty of securing photographs of monocular movements that are significant without reference to the behavior of the other eye even when both eyes are open. There is a very obvious case in Fig. II 4 , between 89 and 98 , and another in Fig. II 5 , between 59 and 64 , in which divergent movements of the two eyes are made up of two essentially different components: first, of a general oblique component, and second, of a horizontal component which must be explained as a corrective movement to effect a more complete divergence than was attained in the oblique movements. There are a number of other cases in the figures here reported where the eye movement is of the same general type on one side but not on the other. Thus, in Fig. I 14 the movement of the right eye between 52 and 64 is of the form under discussion, whereas the corresponding movement for the left eye is of a much more complicated character. The same is true in Fig. I 5 when we compare the movements of the right eye between 31 and 36 and the corresponding movements of the left eye. Furthermore, it will be seen by considering the movements of convergence reported in Figs. II 4 and I I 5 that there is a reversal in the form of movement in that the horizontal component of the movement occurs at the bottom of the line 
rather than at the upper end. Thus, it will be seen in Fig. I I 4 that the movement between 74 and 77 is a direct reversal in all essential respects of the movement which immediately follows it between 89 and 98 . The movement of the left eye between 44 and 47 in Fig. 114 is of the same type. In Fig. I 15 the movement between 73 and 76 and again the movement between I04 and I08 show the typical form of a final sharp change in the direction of the general movement. When these final adjustments in the movement are related to the whole system of binocular adjustments rather than considered merely as forms of curvature of the eye movement, it will immediately be seen that they constitute finer corrective adjustments of the eye by which it fixates the final point upon which both eyes are to converge or diverge. In other words, the form of the movement is a form of adjustment not a type of natural muscular direction of monocular movement. When the final point of fixation is in the main above or below, there will be a general movement of the eye upward or downward and a finer adjustment which is more nearly in a horizontal plane. We may regard the upward or downward components of these movements as simple sympathetic forms of movement. Since there is a strong tendency for the two eyes to move together they do not reach immediately their respective positions of fixation, but make an error which is always explicable by the principle of sympathetic movement of the two eyes.

Furthermore, the results exhibited in Figs. I I 4 and I I 5 show certain cases in which the simple adjustment described above did not appear. Indeed, there were cases to which we may call attention in which the curvature was in the opposite direction. For example, a clear case of irregular movement appears in Fig. II4 in the case of the left eye between photographs 28 and 32 . The corresponding movement for the right eye conforms very clearly to the type described above as typical, but the movements of the other eye correspond more nearly to the movement which would ordinarily appear in convergent movements. In Fig. I I 5 the same general irregularity is to be observed in the movements of the left eye between photographs II and 2 I and also between photographs 30 and 37 . A slight 
irregularity which throws the whole curve into some confusion is also to be found in Fig. I 5 for the left eye, between 87 and 93. Furthermore, there are in the two figures two movements for the right eye which are as nearly straight as possible. In Fig. II there is a straight movement between 44 and 47 . In Fig. II 5 the same form of movement appears between photo graph II and photograph 28. Indeed, attention may be called to the fact in this figure as in the earlier figures for the same subject that all of the movements of the right eye seem to show a somewhat greater regularity and precision than do the movements for the left eye. We may, therefore, conclude on the basis of these figures that all monocular movements are merely exhibitions of the complex adjustments necessary in bringing the eyes into harmonious fixation. It may be added that the figure here reported for one subject is entirely like in essential character figures obtained from two other subjects also.

A final series of facts to be reported were obtained by photographing the eyes during voluntary convergence and divergence in the effort to fuse stereoscopically two separate points without the aid of any stereoscopic apparatus. Two points were drawn on a plane sheet of paper and the subject was asked to look first at one point with both eyes and then at the other, and finally by voluntary convergence to so cross the optical axes that the left eye should fixate the right-hand point and the right eye should fixate the left-hand point. The result would be the familiar fusion of double images in such a way that three points would be seen; one resulting from the fusion of the two figures in the two eyes and the other two from the monocular effects of the two points in the two eyes.

For this experiment two subjects were available, one of whom, the writer, has long been familiar with this form of adjustment of the eyes and performs it readily and without strain, the other subject is unable to make the adjustment readily. After a good deal of effort he is at times able to bring about the fusion for brief intervals, but it is likely to be lost immediately and it can be secured only by strenuous effort. Fig. I 16 reports the results for the subject who is not easily able to make the adjustment. The form of the figure is some- 
what different from that which has been used in the earlier figures except in Fig. I I I. A continuous vertical line such as that between 5 and 20 indicates that the eye continued for the whole period to fixate a single point. From 20 to 21 both eyes move together toward the left, from 22 to 23 both eyes move together toward the right and so on. It will be noticed by
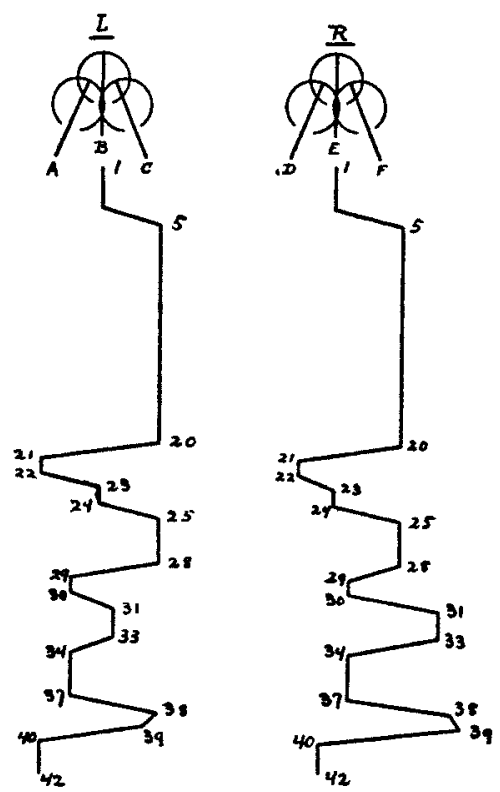

FIG. 116. Subject E. H. Cameron. Two points at a distance of $10 \mathrm{~cm}$. from each other placed at a distance of $45 \mathrm{~cm}$. from the eye are to be fused by a voluntary crossing of the optical axes of the two eyes such that the left eye will fixate the point on the right and the right eye will fixate the point on the left. The successive efforts of the subject to accomplish this voluntary fixation are reported in the figure, the vertical dimensions of the figure being such that distances between exposures are represented by proportionate lengths of vertical lines. Average time of exposures $70 \sigma$ with a possible deviation in individual cases of $2 \sigma$.

considering the length of these various movements that the left eye moves, for example, in the movement 20 to 21 through a greater extent than does the right eye. Conversely, between 30 and 31 the left eye moves much less than does the right eye. There is only one point in the whole series at which the two eyes differ from each other in the direction of their movement, that is, between the photographs 38 and 39 , and this is 
immediately corrected by a movement of the right eye between 39 and 40 much greater in its extent than the corresponding movement of the left eye. The whole figure shows clearly the difficulty experienced by the subject in attempting to bring about any voluntary convergence of the two eyes. $\mathrm{He}$ evidently was dominated throughout these movements by the natural tendency to move both eyes in the same horizontal direction. There is some evidence from the position of the successive points of fixation that he attempted to find a point somewhere between the two objective points given him, and this effort to find an intermediate point is doubtless to be interpreted as his effort to bring about some adjustment which should be a compromise between the two leading tendencies to fixate the right and left points respectively. There is some promise, in the fact that the two eyes do not make the same length of movement, that he would ultimately attain the adjustment necessary to bring about the fusion of the double images. Unfortunately the series of photographs was not continued long enough to record this result, but the accidental separation of the two eyes by moving one more than the other is evidently a suitable means of bringing about the final fusion of the points. This doubtless explains why the subject in question is unable to hold the point steadily for any long period of time.

Fig. I 7 represents a series of movements of voluntary convergence by the writer who, as pointed out a moment ago, is capable of making this movement without serious difficulty. Between 5 and 7 the two eyes move from the point at the right to the point at the left. Between $\mathrm{I} 2$ and $\mathrm{I} 3$ the two eyes come back again to the original point of fixation. The next movement is the first effort at voluntary convergence and it will be noticed that there is a marked sympathetic behavior, both eyes moving toward the left between $I_{5}$ and 16 . The right eye now continues its movement toward the left until it succeeds in fixating the point at the left. This is accomplished in photograph $2 \mathrm{I}$. The left eye, on the other hand, by a succession of movements between 16 and 22 gradually comes back to the position which it originally held at I 5 . The left eye thus returns to the fixation of the right-hand point. Indeed, there 
was no reason so far as the physical relations of the fovea and the right-hand spot were concerned for any movement whatsoever of the left eye when the voluntary convergence began. There was, however, in keeping with all of the facts which have been reported in the earlier cases, a definite sympathetic tendency between the two eyes such that the left eye departed from its fixation of the right point in sympathy with the right eye and was then obliged to make a series of corrective adjustments until it should again fixate the right point. From 22 to 28 the eyes were held in voluntary convergence in the crossed position attained by the preceding movements. From 28 to 29 there was a return to the fixation of the point at the righthand side. Here, again, it will be observed that there is a strong sympathetic tendency between the two eyes. Indeed, the behavior is exactly analogous to that which was described in connection with the series reported in Fig. 104. In Fig. IO4 the left eye was, so far as the objective relations were concerned, under no necessity of movement. It was, therefore, more than in any other case dominated by the sympathetic impulse to move with the right eye, which was objectively under the necessity of long movements. The rest of Fig. II 7 will be easily understood after the descriptions which have been given. One notices, furthermore, that the tendency toward sympathetic action decreases in extent as the subject increases in experience with this particular adjustment. It is a familiar observation to anyone who has performed these movements of voluntary convergence that the successive efforts to fuse two given objects are less and less difficult until fatigue sets in. The photographs in this series were not continued long enough to show any marked effects of fatigue.

Fig. I 8 represents a series of efforts on the part of the subject to fuse two points by divergent movements. For this purpose the two points must be somewhat nearer than the two points in the earlier experiment in voluntary convergence. Indeed, the two points upon which the subject is to voluntarily diverge the optical axes can not be further apart than the pupils of the two eyes. The whole figure was in this case held somewhat nearer to the face, with the result that the amplitude of 
the movement from one point to the other is approximately the same as the amplitude of movement in the case of voluntary convergence. The movements of voluntary divergence

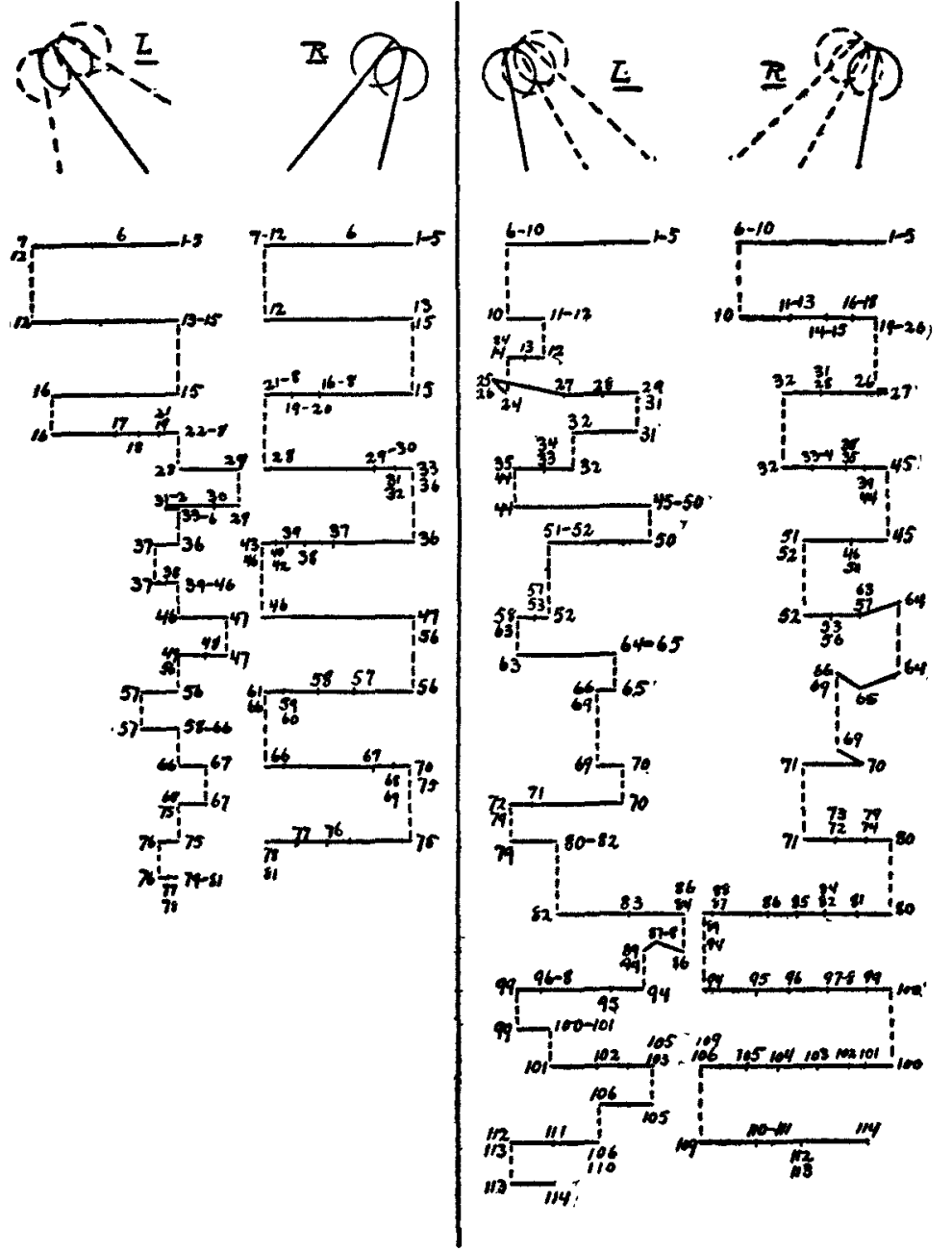

Fic. I17. Subject C. H. Judd. Showing voluntary convergence such as to fuse two points $10 \mathrm{~cm}$. apart, situated at a distance of $50 \mathrm{~cm}$. The first two movements reported in this figure are lateral movements from one point to the other without any effort at convergence. Average time of exposure $89 \sigma$ with a possible deviation in individual cases of $3^{\sigma}$.

FIG. II8. Voluntary divergence in the effort to fuse two points held at a distance of $35 \mathrm{~cm}$. and separated by a distance of $5.5 \mathrm{~cm}$. Average time of exposure $92 \sigma$ with a possible deviation in individual cases of $3^{\sigma}$. Subject $\mathrm{C}$. H. Judd. 
are always more difficult for the writer than movements of voluntary convergence. This statement hardly needs to be made in view of the clear evidence to this effect which appears in the series of photographs. The final position of the eyes in this case when fusion has been attained should be for the right eye the position occupied in photograph 5, or at least approximately in this general position, while the left eye should correspondingly occupy a position of fixation corresponding to that held in photograph 4 . It will be observed that in 14, 35, $58,72,99$ and 1 i 2 the left eye is in such a position as to indicate fixation of the left-hand point. The right eye is in a position which indicates fixation of the right-hand point at 27,45 , $64,80,100$. Obviously the center of fixation for the right eye must be regarded for practical purposes of fusion as lying somewhat further to the left than these particular positions which have just been recorded, for the eye does not continue at 27,45 , etc., for a sufficiently long period to give the opportunity for definite fusion. Positions 19, 39, 57, 97 and I I4 are maintained for a longer period and would seem to constitute the positions of relatively permanent fixation. There is obviously also some tendency for the left eye to fixate permanently the region which lies somewhat to the right of the positions corresponding to position 6 . It would, therefore, seem to be true that in voluntary divergence the optical axes are not brought into a position of direct fixation upon the point, but the eyes are so adjusted that the points to be fused fall approximately at the centers of vision, though in reality somewhat at one side. This confirms the general results reported throughout the earlier investigations of eye movements both in the Yale Studies and in the paper of Dr. Dearborne, ${ }^{1}$ where it is shown that there is no definite center of fixation, but a somewhat extended area which is entirely satisfactory to a subject.

There are a number of other characteristics in Fig. I 18 which are worthy of special mention. Numerous evidences of sympathetic tendencies of movement in the two eyes are apparent. Thus, between Io and I I both eyes move toward the right. The left eye then returns to its original point of fixa-

\footnotetext{
${ }^{1}$ Columbia Archives of Psychology, No. 4, 1906.
} 
tion between 12 and 14 , while the right eye by a series of stages comes to the fixation of the right-hand point at 19 . Again, between 50 and $5 \mathrm{I}$ both eyes move toward the left between 52 and 58 ; the left eye continues in this movement toward the left, while the right eye by a series of stages returns to a position of fixation at the right in photograph 57 .

There are in the later part of the figure two curious examples of the difficulty sometimes observed in making movements of voluntary divergence. It will be seen that between 82 and 84 both eyes converge very notably. The same is true between 100 and ro6. The movement of voluntary convergence, as indicated above, is easier and more fully developed than the movements for voluntary divergence. Consequently, when two points are presented to the subject there is a tendency at times to execute the movement of convergence even when the movement of divergence is intended. Indeed, it is frequently true that when the observer intends to secure fusion by voluntary divergence he secures fusion which ultimately proves to be fusion by convergence, although he may be for the moment quite unconscious of the failure to diverge and the actual fact of convergence. This reversal of the movement may also be connected with the fact that the eyes were becoming somewhat fatigued after the earlier series of efforts at voluntary divergence.

It remains in referring to the photographs to call attention to one or two general characteristics which appear in a number of the different plates. The first few adjustments of the eyes are very frequently different in character from the later adjustments. This has already been pointed out in connection with Fig. I I 7 , where the sympathetic movement was very marked between photographs 15 and I6. In Fig. I I 5 it will be observed that the movements toward the end are more regular in character than those at the beginning. In series I I 3 a very radical change in the character of the movements appears. In Fig. IOI a good illustration appears of a very radical readjustment at the beginning of the movement of the left eye. These instances tend to confirm the statement made in the first reports of this method of photographing the eyes, that it is very desir- 
able for the movements of the eyes to be recorded through more than one adjustment. A single adjustment is very likely to consist in a mere preparation for the later activities, which often become very much more regular in character after the first preliminary adjustments.

The second general fact is that in all of these adjustments there is a tendency for one or the other eye to depart either for a single photograph or for a short series from the direct line of movement. This is illustrated in Fig. I I 8 at photograph 64 and again in photographs 87 and 88 . The same general tendency appears in the case of subject G in Fig. I I2, photograph 36. Photograph 26 in Fig. 1 Io is another illustration of the same type. Photograph 36 in Fig. I03, in Fig. I 02 photographs 47,90 and 126 for the right eye show these same general characteristics. These departures of the eyes from the definite line of movement, especially in a vertical direction, are probably to be explained as due to muscular tensions in the superior and inferior muscles. They are not essentially different in character from the slight readjustments necessary in the lateral directions; they appear, however, somewhat more irregular because the main tendency of movement in all of these cases is in the horizontal rather than in the vertical directions.

The relation between the eye movements reported in this paper and the processes of perception to which these eye movements are related can not be defined in any simple formula of sensations of movement. It is perfectly evident that the binocular fusion of figures which is attained through the completion of movements of convergence and divergence is a process which involves much readjustment of natural tendencies toward sympathetic lateral movements. The evidence has been presented in sufficient fullness to make it clear that there are certain natural individual tendencies of movement in the eyes of different persons, and certain forms of behavior simpler than convergence and divergence, which tend to creep in during any series of fixations of near and remote objects. These irregularities of eye movement, as we may very properly call them from the point of view of completed convergence, are 
seldom if ever presented to normal consciousness and certainly do not constitute positive contributions to the perceptual process. Indeed, it is necessary for us to assume that perception consists in some process which overcomes these irregularities in convergence. There must be some guiding motive which brings together the two eyes in spite of thcir tendencies to follow forms of movement which are simpler than those required for successful convergence.

This superior motive which stands above eye movements and controls them is certainly not explicit intention on the part of the observer to direct the eyes in their action, nor is it an explicit recognition of any irregularities after these irregular movements have been executed. One can by careful attention to his visual experiences become more or less clearly conscious of the fact that an elaborate adjustment is required for perfect recognition of objects upon which the gaze is fixated. Professor Dodge has made the very keen observation that there is always a period of what he calls 'clearing up ' whenever a visual object is fixated. A little practice makes it possible for any one to observe this period of 'clearing up,' especially if the visual adjustment is from a remote to a near object. The recognition of such a clearing up period is as explicit a perceptual recognition of irregularities in eye movement as one is likely to attain. What the clearing up process actually consists in or what are the irregularities in eye movement which precede it no one can describe through his introspective observations. This is evidenced by the fact that though a great variety of observers have attempted to deal with the problem of binocular adjustment in movements of convergence and divergence, their observations are relatively incomplete as compared with the photographic evidence which can be secured in objective study of these adjustments.

The lack of explicit consciousness of eye movements that shows itself in lack of recognition of the irregularities in these movements which are present in obedience to the sympathetic tendencies of the two eyes, argues for a lack of direct relationship between visual perception and sensations of eye movements. It may be said by the defenders of the eye movement 
theory that it shows merely the impossibility of analyzing movement sensations out of the total complex of visual percep. tion. The sensations are present, these defenders will hold, and are of cardinal importance in determining the recognition of position, but their importance is not in their own specific quality and intensity, but rather in their relation to the other factors involved. In answering such a statement it can be pointed out that many of the phases of movement are in direct opposition to the whole process of convergent and divergent fixation. The eye movements not only are not analyzed out of the total situation, but many of them are in direct opposition to the character of adjustment which the subject is aiming to attain. Furthermore, they are not only in opposition to the binocular adjustment, but they are of a distinctly lower order than the binocular adjustment itself. These evidences go to show, in spite of all that has been written with regard to the sensations that result from these movements and especially with regard to the tensions toward movements which are frequently regarded by the defenders of the movement sensation theory as of greater importance than the movements themselves, that the movements are overcome and redirected rather than relied upon to accomplish the adjustment.

We can not, however, be completely satisfied with mere negation. When we have accumulated the evidence to show that there can not be a direct relation between the sensations derived from irregular eye movements and the final completed percept, we must, on the other hand, recognize that there is the closest possible relation between the final adjustment and the complex percept of position in depth of the object fixated. In other words, the perceptual process and the movement are ultimately brought into harmony, though it is obvious that this harmony is obtained through effort and involved many irregular and conflicting factors. That there should be an ultimately successful binocular adjustment, in spite of the conflicting tendencies shown in the results above described, is the strongest argument for the recognition of a relation of fundamental importance between perception and movement. Furthermore, there can be no doubt in the light of the facts described in this 
paper that the binocular adjustments differ in complexity and in the degree of effort necessary to attain them from certain simpler forms of adjustment.

In attempting to explain the complex forms of binocular adjustment we must recognize the fact that the adjustments themselves are in response to some demand which is of superior importance in individual life to the elementary tendencies which they overcome. The natural temptation will immediately arise to dispense with the whole question here involved by saying that the binocular motor adjustments are controlled by the retinal images. This will serve very well as a short formula if we wish to discuss merely the relation between sensations of movement and retinal sensations. It is undoubtedly true that the retinal sensation is in a certain sense the controlling factor in the total binocular fusion. It is only when like stimuli act upon the two foveas that the eyes can come to rest and the converging of the lines of regard as a condition preliminary to holding the two eyes fixed upon a certain point in spite of their natural tendency to move together in a lateral direction, is undoubtedly related to the superior significance in experience of the retinal sensation from the two foveas.

The short formula is, however, incomplete until some clearness can be reached as to the nervous organization by which the retinal excitations are related to movement. Sherrington ${ }^{1}$ has made it clear that the retinal excitations are sources of independent ceitral processes. He has further called attention in his book The Integrative Action of the Nervous System, pp. 385 , et seq., to the fact that the fusion of these independent central sensory processes is due to their union as they pass to the motor centers. Experiments on central localization have shown in agreement with the functional fact reported in this paper, that the movements in the two eyes which result from the stimulations of the occipital visual area are of the type described above as sympathetic lateral movements; that is, whenever this first cortical area in the occipital region is stimulated there is a tendency for the two eyes to move laterally in

${ }^{1}$ Sherrington, ' On Binocular Flicker and the Correlation of Activity of Corresponding Retinal Points,'British Journal of Psych., Jan., 1904, pp. 26-60. 
the same direction. It is only when one of the higher association centers situated further forward in the cerebrum is aroused to action that there is any tendency toward convergent movement of the two eyes. Convergent movement is thus obviously dependent upon a higher form of associative activity in the central nervous system than that which is demanded for mere lateral movement of the two eyes in sympathetic activity. Thus we see that while the short formula which holds that retinal images guide the adjustment of convergence and divergence is satisfactory for the statement of the contrast between sensations of movement and retinal sensations, it is by no means acceptable as a complete statement of the whole formula of fusion. Fusion in this case evidently involves a coördination of impulses of an elaborate associative type. If that coördination is of the simple type provided for in the first visual region of the cortex, the motor adjustment will be of the more elementary form. If, on the other hand, convergent coördination is present, this appears as a higher type of coördination than that which is provided in the simpler sympathetic adjustment, and for the more elaborate coördination higher centers must be drawn into action and correspondingly a higher form of experience must be expected.

We are thus led from our considerations of the relation between retinal images and movement process to recognize the fact that after eliminating sensations of movement we must recognize the paramount importance of motor adjustments in an entirely different sense. The important question is one of coördination of impressions in the development of more and more elaborate forms of response. It is not a question of how fully we are informed through sensations of the adjustments after they are made, it is rather a question of how elaborately we are able to respond to sensory impulses through higher forms of associative coördination. Experience will thus be explained not so much by the factors which enter into it as by the forms of elaboration to which these factors may contribute. The movement is not significant because of its peripheral elements which, as this report has shown, involve an oscillation backward and forward with a resultant tendency 
toward gradual convergence or divergence. The movement is rather significant because as a total form of activity it is worked out as a response to certain complicated sensation processes which are themselves unified and fused in experience in the development of the unitary motor adjustment. The unity of experience is not to be described by regarding the one group of sensation factors as in control and the other elements as clustered about the dominant sensations. The whole experi. ence is to be regarded rather as a succession of associative processes in which the end of the process may very properly be described as a motor adjustment to all of the sensory elements. The stages of that process may be variously complicated by monocular tendencies and sympathetic tendencies in one direction or the other. But these secondary or complicated elements are all of them significant merely as indications of earlier stages of coördination and fusion, not as contributing any positive factors to the present fusion. Indeed, there are many evidences that the preliminary motor adjustments are not important for the final coördination, but mere incomplete and partial phases of the total process. Thus, a consideration of the time required to correct one of the irregular movements which appears whenever one eye is distracted from the path of convergence in order to sympathize with the other eye is so short that there is no possibility of clear perceptual consciousness intervening between the execution of the movement and its correction. There seems to be a momentary oscillation between phases of adjustment. The first tendency is for the two eyes to move sympathetically in a given direction. Before this tendency can be consummated in any such way as to come to clear consciousness and invite a voluntary change in the direction of one of the eyes, a second phase of movement sets in which obeys the demands of higher coördination. Taken by itself, each phase of sympathetic and corrective movement seems to be an involuntary or reflex adjustment of the eye. On the other hand, when we consider the total process of conscious perception and motor coördination, we recognize that the essence of the process is not in the single factors but in the combination. As we saw in Fig. I 17, the mastery of the sym- 
pathetic form of movement in the course of a series of convergent and divergent fixations becomes more complete as the series of adjustments proceeds. It would seem, therefore, that the clearer and clearer perception of a given situation results in a more and more affective subordination of the discordant adjustments to the demands of the total adjustment. The total process is thus shown to be a higher form of coördination than any of its elements and to stand in a very different relation to conscious experience.

If for any reason the coördination is delayed, the separate factors may assert themselves. Thus, in the adjustment indicated for Fig. I I6, the most characteristic fact in the subject's experience is the utter confusion of his visual percepts. It is quite impossible for him to guide his visual activities because the single factors assert themselves in such a way as to prevent final coördinated activity. Again, the observation that prior to the final adjustment there is a clearing up period in experience is a fact of the same type. These cases of incoördination or confusion form the most productive starting point for an explanation of the nature of perceptual fusion. Whenever one is confronted by a mass of experiences for which he has no definite mode of response, that mass of experiences is confusing just because it distracts him in such a way as to attract a great variety of conflicting adjustments. He tends to move now in one direction, now in the other, without succeeding in performing completely any single reaction. We may say of his movement on the one hand that it is uncoördinated. We may say of his experience on the other that it is entirely lacking in unity and in clearness. Nor will the unity and clearness of experience and the corresponding coördination of behavior result by any mere adding together the different elements of sensory experience or motor response. The fusion must be worked out by bringing about such a relation between the different phases of adjustment that they shall all be included and combined into a new form of coördinated completeness which shall have a unity of its own type, a unity superior to that of the elementary forms of sensation and activity which it embraces.

Such a formula as this is applicable in the discussion of all 
kinds of perceptual development. There can be very little doubt that an infant finds itself overwhelmed with a great mass of sensory experiences by which it is constantly distracted. The few forms of adjustment which are clearly worked out through instinct in the infant are the only clear-cut forms of adjustment which it has and its earliest attention is evidently directed toward the objects to which these instinctive coördinations apply. Undeveloped adult percepts certainly illustrate the formula of incoördination of factors. Thus, if one looks at a new and complex visual pattern he fails to recognize clearly the complex figure because the mass of lines is so distracting that each draws his attention away from the other. Both in the case of the infant and the confused adult the surest method of attaining a clear percept of any given phase of his environment is to gradually work out a practical adjustment in which activity and sensory experience shall be unified by subordination of most of the elements to a few dominating factors. That is, instead of making a succession of reflex responses to a great variety of different factors, the subject must ultimately reject some of these reflex tendencies. If they are so strong that they tend to assert themselves in spite of the dominating center upon which he would converge, he must then work out a higher form of coördinative adjustment whereby he shall be able to recover from the strong reflex tendency which has led him astray. He must, in short, by some means or other succeed in overcoming the great manifold of distracting experiences. When he has thus succeeded in withdrawing from many avenues of impulsive adjustment, he may ultimately work out a form of adjustment which will be of a much more unitary and stable order. He will then find that there has been going on in his sensory experience a process of selection whereby certain factors have been distinctly subordinated to a few dominant elements of experience.

The dominant elements in such a process can not now be described as having asserted themselves through the complete suppression of the other elements; nothing is suppressed in the sense of being eliminated. The sensory processes can not be shut out, and the energy poured into the central nervous system 
by the minor sensation can not be ignored. The selection of the particular centers of experience and adjustment is rather a matter of relations in which all factors are included. The adjustment instead of being merely negative includes the total individual. The concentration is not merely a matter of sensory elements, it is not merely a matter of muscular adjustments; it is a matter of general relating and placing of factors in advantageous relations.

There has been in the discussion of perceptual fusion in psychology some tendency to confuse two distinct characteristics of percepts which characteristics have, so far as their conditions are concerned, entirely different types of origin. First, every percept has the characteristic of inclusiveness, and in the second place every percept has unity. The inclusiveness of a percept is ordinarily much larger than the descriptive analysis of percepts by introspection would admit. One does not ordinarily recognize, for example, in the binocular adjustment which we have been studying, the natural tendency to recognize a great variety of objects in the lateral regions of vision, although these apparently ignored objects undoubtedly enter into the determination of eye movements. One does not recognize through any introspective analysis the fact that when a sympathetic movement is performed by the two eyes there is an increase in the confusion of retinal images sufficient to call for an immediate readjustment. One does not recognize explicitly, as even the most ardent defenders of movement sensation theories are prepared to admit, the sensations of movement which come from the muscles of the eye or the sensations of contact which come from the surroundings of the eyeball during its adjustments. Indeed, if these various factors which are unquestionably contributory to the total percept came into any clear recognition, they would constitute a disturbance of the perceptual process. They are included but are not recognizable factors. They are fused with the chief elements which in this case consist of the retinal elements, but their fusion is of such character as to subordinate them to the main sensations. The main sensation would have no perceptual setting if it were not for these surrounding sensation factors. 
Inclusiveness thus emphasizes the great variety of factors entering into percepts. In sharpest contrast with the inclusiveness of percepts stands their unity. The more factors included in a percept the more obvious the demand that they shall be reduced to a single coördinated system. Unity must be sought elsewhere than in the manifold of sensory factors. Unity is, accordingly, wrought out of experience by counteracting the tendencies that grow out of wide inclusiveness. Inclusiveness may be regarded as the primary character of consciousness, and in so far as fusion is used to describe the inclusiveness of a conscious state we may say that inclusiveness is the most elementary fact in mental life. It is certainly more elementary than concentration on single clearly defined experiences. A single clearly defined experience is a late product of perceptual development. It comes as a result of the narrowing down of inclusiveness; it does not in any sense of the word arise by any process of mere addition of factors to each other nor by a mere ignoring of factors.

The notion of addition or subtraction should be eliminated altogether from the discussion of perceptual fusion. The only concept which is of any value in the clear explanation of perceptual unity is the concept of coördination. This concept is one which gives us the justification for treating the processes of perceptual fusion as processes of unification, and unification, as will be seen from the foregoing discussion, is totally different from inclusiveness. When one succeeds in building up in his experience a compact percept, he has not succeeded in doing this by bringing into consciousness factors which were not there at the outset, nor has he attained it by bringing together factors which formerly existed apart. $\mathrm{He}$ has done it in most cases by utilizing certain adjustments which were all present at the same time but mutually incompatible, and he has developed a form of adjustment which can in some measure reconcile the incompatible factors. Consider, for example, in terms of the material presented in the earlier part of this paper the mass of retinal, muscular and tactual sensations which are involved in any act of binocular convergence or divergence. Consider, on the other hand, the clearness with which con- 
sciousness moves to its perceptual goal in spite of all of the elements of experience. So far as this binocular adjustment of convergence is to be described in terms of inclusiveness, it comprises a great number of distracting and unnecessary elements. When, on the other hand, we recognize how the adjustment of the two eyes overcomes all of the distractions that precede it, we see how closely related are the final motor adjustments of the eyes to our clarified and definite spatial organizations of experience. We bring all the data of sensory experience together and recognize in one act of consciousness the distance between a remote point and a near point at the same time that we accomplish a careful adjustment of the two eyes upon the near point. Both processes involve a subordination of many of the elements of the environment which are constantly impressing the retina and many of the muscular adjustments which arise from the collateral and unnecessary tendencies of eye movement. This perceptual experience is, however, a compact unitary process which has a certain definite content about which all of the other elements are related, and it derives through its unity and through the compactness of its various elements certain characteristics which the central, highly clarified elements could not possess unless all of the secondary factors had been properly coördinated with, or better, subordinated to them.

The point which we fixate we recognize as having position in space, as having relation to the other factors that enter into visual experience, and the whole group of factors is recognized as completely mastered in a single unitary percept. The unity is by no means the same as the inclusiveness. It is a unique and highly developed fact in which the different sensory elements are made to contribute to a single clearly marked phase of conscious experience.

It has frequently been observed that the movement of binocular coördination in infants is later in its development than the sympathetic lateral movements of the eyes. It is probably true in view of these observations that there is a certain period of infancy during which recognition of position in depth is undeveloped. We certainly can not assume that the infant whose two eyes are not yet coördinated in binocular adjustment 
is deprived of the mass of retinal sensations that come to him from the ordinary impact of light upon his two organs of sense. There must be unlimited confusion in his experience because of the tendency which many points in the field of vision have to attract lateral movements to themselves, and when these lateral movements are undertaken they not only do not prove satisfactory, because they bring new confusing elements into experience, but they furnish a motive for experiments in new types of ocular adjustments which are distinct from those which arise easily and reflexly. The infant, in other words, must have a vague consciousness that his adjustments are increasingly inefficient, when he moves his eyes in simple lateral movements in the presence of two bright points which lie at different distances from him. To hold that the infant is in any sense of the word clearly conscious of what we have here stated in an abstract logical form is, of course, a fallacy which can easily be guarded against by reformulating our statement and putting it in impersonal terms. We may say that there is confusion in consciousness from the time the infant comes in contact with two bright points at different distances in depth. This increasing confusion must continually excite new motor adjustments until by some chance a form of motor adjustment appears which will bring the two foveas into the familiar relation to the bright points. The analogy suggested in Fig. I 15 has already been pointed out as perhaps the best analogy with which to inforce this point. If the infant were not capable of recognizing the confusion in experience in some fashion or other, he would simply go forward with the sympathetic lateral movements which are the easy forms of adjustment. There is no reason to believe that he would ever rise above this level any more than the subject reported in the photographs in Figs. I05 and 106 who, having no retinal images to become confused, has no motive whatsoever for undertaking new forms of visual adjustment above those of the simple sympathetic type.

The confusion in the earliest stages of impression must be recognized as a motive for effort until there shall be substituted for the confused mass of experience a more satisfactory or highly selected type of experience. This organized mass of 
experience will be no less inclusive than at first, but it will be more completely unified. Furthermore, it should be noticed that the rearrangement is not a merely static process. It does not consist in the adding together of sensory factors which are alike in quality, but there is a progressive combination of all of the different factors of sensation and of activity until the reflex tendencies aroused by different sensations shall be combined into an all-inclusive unitary tendency. Such a formula as this does not emphasize the sensory qualities of two retinal stimulations, it emphasizes rather the importance and necessity of a single adjustment which shall bring together stimulations through a single motor adjustment. The formula is both sensory and motor. It is a formula dealing with coördination of elements rather than with the elements themselves. The general grounds for the adoption of such a formula as this have been dealt with by the writer in an earlier paper. ${ }^{1}$ The formula serves so admirably to explain the results in this series of photographs and at the same time clears up so completely the difficulties which interfere with any effort to give a purely analytical account of binocular fusion, that the present discussion must be accepted not merely as an application but also as a confirmation of the position assumed in the earlier paper.

\footnotetext{
${ }^{1}$ Vol. No. I., New Series, Yale Psychological Studies, pp. 199-266.
} 